
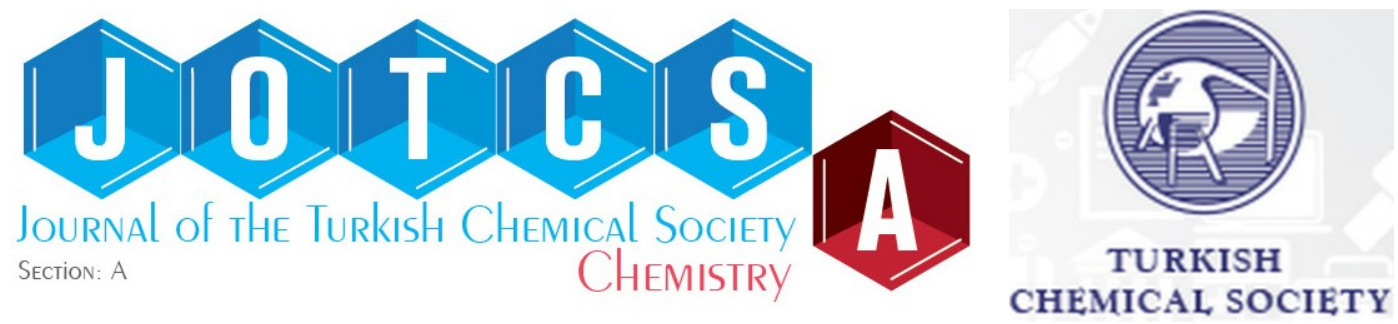

\title{
Chemical Constituents of Rumex abyssinicus Roots and Evaluation of Its Antimicrobial Activities
}

\author{
Muaz Shifa $\triangle$ D , Dele Abdissa $\triangle D$, Tsegaye Girma Asere* $\triangle$ iD
}

Jimma University, College of Natural Sciences, Department of Chemistry, P.O.Box 378, Jimma, Ethiopia.

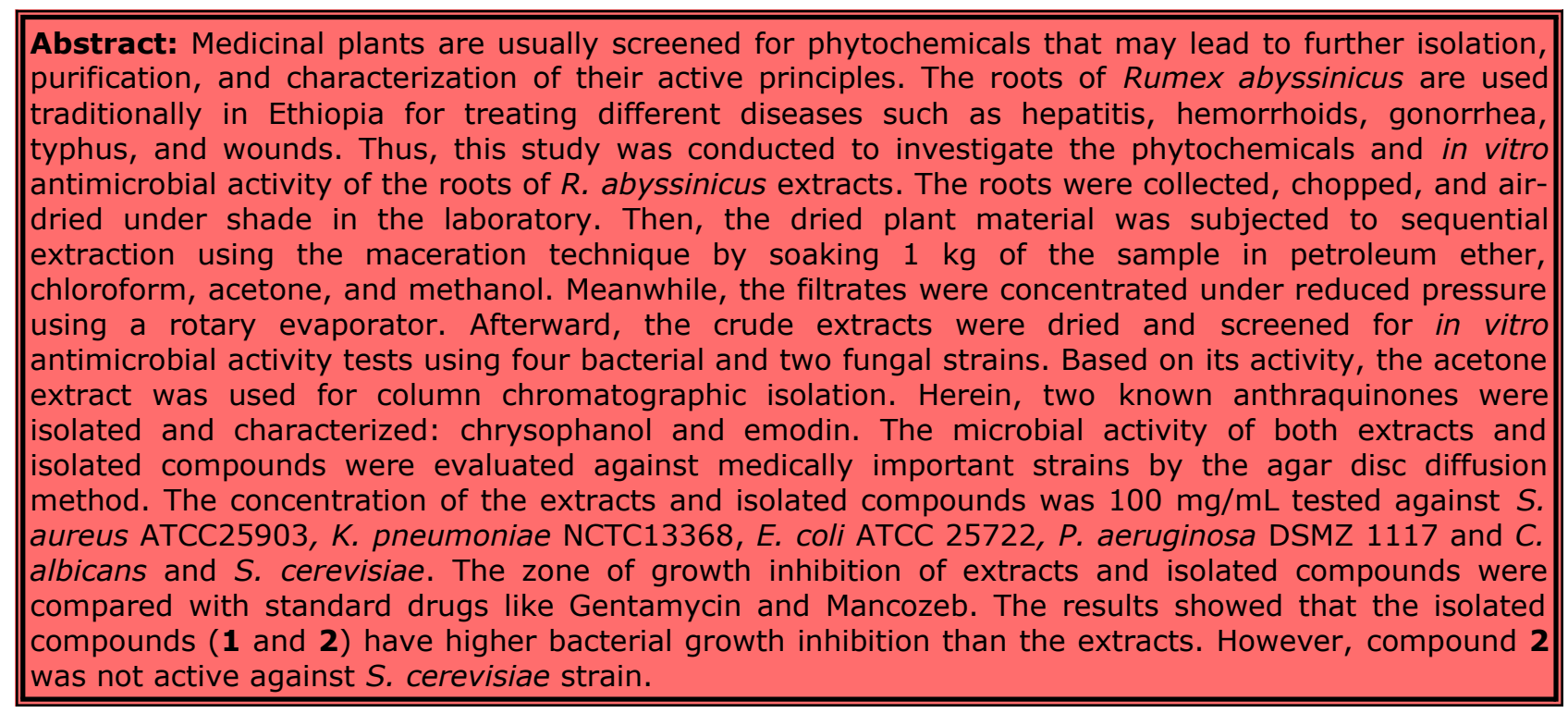

Keywords: Rumex abyssinicus; chrysophanol; emodin

Submitted: September 20, 2020. Accepted: November 05, 2020.

Cite this: Shifa M, Abdissa D, Asere TG. Chemical Constituents of Rumex abyssinicus Roots and Evaluation of Its Antimicrobial Activities. JOTCSA. 2021;8(1):21-46.

DOI: https://doi.org/10.18596/jotcsa.797560.

*Corresponding author. E-mail: tsegaye96@gmail.com.

\section{INTRODUCTION}

Medicinal plants (MPs) are the abundant bioresources of medical substances of traditional systems of medicine, modern medicines, nutraceuticals, food supplements, folk medicines, pharmaceutical intermediates, and chemical entities for synthetic drugs (1). Since time immemorial, different parts of medicinal herbs have been used to cure specific ailments (2). They are recognized for their ability to produce a wealth of secondary metabolites, and mankind has used many species for centuries to treat a variety of diseases (1). Many of the natural products (NPs) have been shown to present interesting biological and pharmacological activities and serve as the starting point in the development of modern medicine (3).

A number of modern drugs have been derived from natural sources, many based on their traditional medicinal claims. The plant products used in the 
treatment of diseases could be obtained from barks, leaves, flowers, roots, fruits, or seed parts of the plants (4). The use of biological resources for various therapies has been known in many different parts of the world, especially in remote regions where traditional medicines (TMs) provide an alternative to the modern health care system (5). Many people in developing countries still use TM due to its low cost and availability (6). Over $80 \%$ of people in developing countries rely on TM for primary health care needs, of which a major proportion corresponds to plant extracts $(6,7)$. The phytochemicals isolated from these plants have shown in vitro and in vivo biological activities (8).

Ethiopia is the home of many plant species that are commonly used in many disease treatments by local healers (9). Some of the factors attributed to these facts are accessibility, affordability as compared to modern drugs, socio-cultural background, and their effectiveness against several health problems (1). For example, $R$. abyssinicus is a widely spread medicinal plant in the highlands of tropical Africa and is a common weed of cultivated lands or disturbed grounds ranging from North Africa to Ethiopia at altitudes between 1200 and $3300 \mathrm{~m}$ (10). It is a perennial herb, which grows up to $3 \mathrm{~m}$ tall, with a thick, fleshy rhizome. The plant is endemic to Ethiopia and it is referred to as mekmeko in the Amharic language $(11,12)$.

The genus Rumex belongs to the family Polygonaceae, which consists of about 200 species. Most of the species of Polygonaceae contain a large number of bioactive compounds such as anthraquinones, flavonoids, terpenes, naphthalenes, stilbenoids, and steroids, flavonoid glycosides, leucoanthocyanidins, and phenolic acids (11). Traditionally, people use different parts of Rumex species to treat several health problems such as infections, diarrhea, constipation, mild diabetes, oedema, jaundice, skin, liver, and gallbladder disorders and inflammation, and as an antihypertensive, diuretic and analgesic preparation $(9,13)$. The decoction of the leaves or root powder of $R$. abyssinicus is taken as a vermifuge. It is also used to treat malaria, gonorrhea, poisoning, hepatitis, constipation, sciatic neuralgia, hypertension, migraine, rheumatism, breast cancer, stomach distention, earache, hepatic diseases, hemorrhoids, typhus, rabies, and wound (14). The roots of $R$. abyssinicus are reported to possess antibacterial activity against Streptococcus pyogenes (15). Its antifungal activities were also tested against several fungal pathogens (Aspergillus fumigatus, Aspergillus flavus, Aspergillus versicolor, Aspergillus niger, Blastoschizomyces capitatus, Fusarium oxysporum, Fusarium moniliforme, Fusarium semitectum , Pythium sp., Rhizopu ssp.,
Sporotrichum sp., and Thermomyce ssp.) and results showed its promising activity (16).

For this reason, medicinal plants are considered a chemical factory as it contains a multitude of chemical compounds which are suggested to be natural bioactive like alkaloids, glycosides, saponins, resins, oleoresins, sesquiterpene, lactones, anthraquinones, and essential oils and fixed oils (17). The emergence of antibioticresistant microbial strains (including bacterial and protozoan parasites) and the increasing failure of available chemotherapeutics (18) urge the search for microbiologically active MPs. Hence, the bioactive phytochemical constituents present in the plant play a significant role in the development of medicine and drug discovery. Therefore, herein it was aimed to carry out phytochemicals isolation and evaluation of their in vitro antimicrobial activities of extracts from the roots of $R$. abyssinicus.

\section{EXPERIMENTAL SECTION}

\section{Chemicals}

Chemicals used for this study were petroleum ether, chloroform, acetone, ethyl acetate, silica gel 60-120 mm mesh size. Dimethyl sulfoxide (DMSO), Mueller Hinton agar, and nutrient broth were used for the antimicrobial test. All chemicals and reagents used were of analytical grade.

\section{Apparatus and Instruments}

Apparatuses such as rotary evaporator (Heidolph, Germany, laboratory 4000), round bottom flasks, measuring cylinder, filter paper (cotton swab), weighing balance (model NWT100001X) oven (N5OC GENLAB WIDNES, England) were used. Analytical Thin Layer Chromatography (TLC) was performed on precoated silica gel $60 \mathrm{~F}_{254}$ plates. Incubator (Gene lab incubator) and Hood (CLB201-04, vertical laminar cabinet) were used for the antimicrobial activity studies. Glass column chromatography (500 mm, B-34/35) and UV chamber ( 254 and $365 \mathrm{~nm}$ ) were used for isolation of compounds. The NMR spectra were recorded on an Avance $600 \mathrm{MHz}$ spectrometer (Bruker, Billerica, MA, USA) using the DMSO solvent.

\section{Sample Collection and Preparation}

The roots of $R$. abyssinicus were collected from Gomma District, Jimma Zone, Oromiya Regional State, Ethiopia, in July 2019. Then, it was roughly washed with tap water, chopped into smaller pieces, and air-dried under a shade at room temperature in the laboratory. The air-dried sample was homogenized into a suitable size to increase the rate of solvent penetration into the cells by using mechanical grinding. Finally, it was subjected to organic solvent extraction. 


\section{Extraction and Isolation}

The air-dried root sample of $R$. abyssinicus ( $1 \mathrm{~kg}$ ) was sequentially extracted by soaking in petroleum ether, chloroform, acetone, and methanol $(2 \times 2.5$ $\mathrm{L})$ each using a maceration technique at room temperature and was kept for $48 \mathrm{~h}$. The extracts were filtered with filter paper, plugged in cotton, and concentrated using a rotary evaporator under reduced pressure; the yellowish crude extracts were kept in a desiccator until dryness for further experimental purposes. Then, the crude products weighing $5.45 \mathrm{~g}(0.55 \%), 8.50 \mathrm{~g}(0.85 \%), 14.50$ $(1.45 \%)$, and $14 \mathrm{~g}(1.40 \%)$, respectively were obtained. Meanwhile, the four extracts were applied for in vitro antimicrobial activity test and TLC analysis to continue the isolation of pure compounds, with the product having promising bioactivity against the selected bacterial and fungal strains.

Isolation of pure compounds was continued using the crude products demonstrating promising activity against the strains and good TLC profile. Among the four crude extracts, acetone extract has shown the highest zone of growth inhibition against bacterial and fungal strains. Thus, based on its bioactivity and TLC profile, it was subjected to column chromatographic separation. Petroleum ether/ethyl acetate combination showed better separation of the compounds on TLC tests. Initially, the column chromatography was packed with silica gel (60-120 mesh size) just by activating in an oven at $100^{\circ} \mathrm{C}$ for $2 \mathrm{~h}$. Then, the fine powder of the sample acetone extract $(14.5 \mathrm{~g}$ ) was loaded to the column chromatography.

The elution was started with petroleum ether and increased the polarity using 1 up to $100 \%$ ethyl acetate. Meanwhile, a total of 148 fractions were collected in a $20 \mathrm{~mL}$ small beaker for each. The first 30 fractions were merged after TLC analysis. Using TLC and $R_{f}$ value results, fractions with similar $R_{f}$ values were combined. Fractions 52-65 were combined and washed repeatedly with nhexane to afford compound $\mathbf{1}(0.40 \mathrm{~g})$. The elution was continued by increasing the polarity of the solvent. The second pure compound $\mathbf{2}$ was obtained from fractions 66-81. It showed one spot and some impurities which were later purified by continuing washing it with n-hexane. Then, a crystalline orange color product of compound-2 $(0.38 \mathrm{~g})$ was obtained. The isolated compounds were characterized by using ${ }^{1} \mathrm{H}-\mathrm{NMR},{ }^{13} \mathrm{C}-\mathrm{NMR}$, and 2D NMR spectroscopy techniques.<smiles>Cc1cc(O)c2c(c1)C(=O)c1c(O)cccc1C2=O</smiles>

1<smiles>Cc1cc(O)c2c(c1)C(=O)c1c(O)cc(O)cc1C2=O</smiles>

2

Figure 1. The proposed structure of compounds $\mathbf{1}$ and $\mathbf{2}$.

\section{Antimicrobial Activity Test}

Test strains and preparation of test samples: Microorganisms used for evaluation of in vitro antimicrobial activities were $S$. aureus ATCC25903, K. pneumoniae NCTC13368, E. coli ATCC 25722, P. aeruginosa DSMZ 1117, C. albicans, and $S$. cerevisiae. These strains were obtained from Jimma University Microbiology Research Laboratory, Biology Department. The in vitro antibacterial and antifungal activities of the crude extracts and isolated compounds were determined against four bacteria and two fungal strains mentioned above using the agar disc diffusion method and was carried out following a standard procedure as used earlier by Abdissa et al. (19). Then, bacterial and fungal stock cultures were incubated for $24 \mathrm{~h}$ at $37^{\circ} \mathrm{C}$ on nutrient agar and potato dextrose agar (PDA) media following refrigeration storage at $4^{\circ} \mathrm{C}$. The bacterial strains were grown in Mueller-Hinton agar (MHA) plates at
$37{ }^{\circ} \mathrm{C}$ (the bacteria were grown in the nutrient broth at $37{ }^{\circ} \mathrm{C}$ and maintained on nutrient agar slants at $4{ }^{\circ} \mathrm{C}$ ), while the fungal strains were grown in PDA media at $28{ }^{\circ} \mathrm{C}$. The stock cultures were maintained at $4{ }^{\circ} \mathrm{C}$. The bacterial and fungal stock cultures were incubated for $24 \mathrm{~h}$ at $37^{\circ} \mathrm{C}$ on nutrient agar and PDA medium.

Active cultures for this experiment were prepared by transferring a loop full of bacterial cells from the stock cultures to test tubes of Mueller-Hinton broth (MHB) that incubated without agitation for $24 \mathrm{~h}$ at $37{ }^{\circ} \mathrm{C}$. A cell suspension of each organism was freshly prepared by transferring isolated colonies selected from a $24 \mathrm{~h}$ agar plate into a broth and the cell density was adjusted to turbidity equivalence of 0.5 McFarland turbidity standards $\left(1 \times 10^{8} \mathrm{CFU} / \mathrm{mL}\right)$ in sterile saline solution. The bacterial and fungal cultures were then streaked onto MHA plate with a sterile cotton swab to obtain 
a uniform thick lawn of growth. Meanwhile, the sterile paper discs $(6 \mathrm{~mm}$ diameter, Whatman No.3) were separately soaked in pre-prepared crude extracts and pure compounds, whose stock solutions were prepared at a concentration of 100 $\mathrm{mg} / \mathrm{mL}$ by dissolving $0.1 \mathrm{~g}(100 \mathrm{mg})$ of the crude extracts and pure compounds were separately dissolved in DMSO before aseptically placed on an already inoculated MHA plate. It was then allowed to diffuse for $5 \mathrm{~min}$ at ambient temperature and then incubated at $37{ }^{\circ} \mathrm{C}$ for $24 \mathrm{~h}$. Gentamycin and Mancozeb $(10 \mu \mathrm{g})$ were used as a standard positive control against bacterial and fungal strains, respectively, DMSO was used as a negative control. Finally, the zone of growth inhibition was reported by measuring diameter using a transparent ruler after $24 \mathrm{~h}$ of incubation.

\section{RESULTS AND DISCUSSION}

\section{Characterization and Antimicrobial activities}

Compound-1 was isolated as a yellowish crystalline solid obtained from the fractions 52-65. Its $R_{f}$ value was 0.65 using $70 \%$ petroleum ether in ethyl acetate as an eluent. The ${ }^{1} \mathrm{H}-\mathrm{NMR}$ spectrum is given in supporting information (SI1), which showed that the presence of five aromatic protons at $\delta_{H} 7.22,7.39,7.55,7.71$, and 7.81 ppm (Table $1)$. Besides, hydroxyl proton $(-\mathrm{OH})$ groups were observed at $\delta_{H}$ 11.93. And ${ }^{1} \mathrm{H}-\mathrm{NMR}$ spectroscopic data of compound-1 showed a singlet proton signal at $\delta_{H} 2.44 \mathrm{ppm}$ representing three protons attached to $\mathrm{C}-3$ of the aromatic ring $\mathrm{A}$. The two broad singlet peaks observed at $\delta_{H} 7.22,1 H$ and $7.55,1 H$ represent the protons attached to $\mathrm{C}-2$ and $\mathrm{C}-4$ of the aromatic ring, respectively. The aromatic protons that are attached to $\mathrm{C}-5$ and $\mathrm{C}-7$ are a doublet of a doublet at $\delta_{H} 7.72, d d, J=12$,
$1 H$, and $7.39, d d, J=6,1 H$, respectively. The pseudo-triplet proton was observed at $\delta_{H} 7.82, t$, $J=6,12(\mathrm{~m}, 1 \mathrm{H})$. These three mutually coupled aromatic protons at $\mathrm{C}-5, \mathrm{C}-6$, and $\mathrm{C}-7$ are in the $\mathrm{ABX}$ spin system. Moreover, there are two chelated protons at the peri-position ( $\mathrm{C}-1$ and $\mathrm{C}-8)$ of the aromatic ring, a highly deshielded proton at $\delta_{H}$ $11.93 \mathrm{ppm}$ and downfield shifted carbonyl signals at $\delta_{c} 192.0$ and $181.0 \mathrm{ppm}$ (Table 1). Thus, the presence of a 1,8-dihydroxyanthraquinone moiety clearly indicates that as it is the chrysophanol (19). And its molecular formula is $\mathrm{C}_{15} \mathrm{H}_{10} \mathrm{O}_{4}$ (12).

Its ${ }^{13} \mathrm{C}-\mathrm{NMR}$ spectrum (SI2) showed 15 signals that represented 15 carbons including one methyl group at $\delta 22.0$, five aromatic carbons at $\delta \mathrm{C}$ : C-2 (124.6), C-4 (120.0), C-5 (119.8), C-6 (137.8), and C-7 (124.9) as evidenced from HSQC data (SI3). Besides, the spectra showed two-hydroxyl carbons at $\delta C 161.8$ and 162.0 , which represent carbons at peri-position and two aromatic carbonyl groups were also observed at $\delta C$ C-9 (192.0) and C-10 (181.0). Therefore, based on the combined spectroscopic data (COSY (SI4), HSQC, HMBC (SI5), and ${ }^{1} \mathrm{H}-{ }^{13} \mathrm{C}$ ), the proposed structure was suggested chrysophanol (Compound 1, $0.40 \mathrm{~g}$ ). Based on this research finding and literature review reports $(19,20)$, Compound-1 was identified as 1,8-dihydroxy-3-methyl-9,10-anthraquinone (chrysophanol) (Table 2, Figure 1). It was reported from the roots of $R$. abyssinicus, where pure compounds were isolated using n-hexane, ethyl acetate, and methanol (20). Other studies reports also indicated that chrysophanol is present in Polygonaceae, Rhamnaceae, Fabaceae, Liliaceae, Asphodelaceae, Buphorbiaceae, Meliaceae, Podocarpaceae, Picramniaceae, and Hemerocallidaceae plant families (21-23).

Table 1. ${ }^{1} \mathrm{H}(600 \mathrm{MHz})$ and ${ }^{13} \mathrm{C}(150 \mathrm{MHz}) \mathrm{NMR}$ Spectral Data of Compounds $\mathbf{1}$ and 2 in DMSO-d 6 .

\begin{tabular}{lcccc}
\hline & Compound-1 & \multicolumn{3}{c}{ Compound-2 } \\
position & $\delta^{1} \mathrm{H}(m, J$ in Hz$)$ & $\delta^{13} \mathrm{C}$ & $\delta^{1} \mathrm{H}(m, J$ in Hz$)$ & $\delta^{13} \mathrm{C}$ \\
\hline 1 & $11.93, \mathrm{~s}$ & 161.8 & $11.96, \mathrm{~s}$ & 161.9 \\
2 & $7.22, \mathrm{~s}$ & 124.6 & $7.11, b, \mathrm{~s}$ & 124.5 \\
3 & - & 149.6 & - & 149.7 \\
4 & $7.55, \mathrm{~s}$ & 120.0 & $7.42, \mathrm{~s}$ & 121.0 \\
5 & $7.72(d d, J=12)$ & 119.8 & $7.06, \mathrm{~s}$ & 109.2 \\
6 & $7.82(t, J=6,12)$ & 137.8 & - & 164.9 \\
7 & $7.39(d d, J=6)$ & 124.9 & $6.55, \mathrm{~s}$ & 108.3 \\
8 & - & 162.0. & $12.04, \mathrm{~s}$ & 166.0 \\
9 & - & 192.0 & - & 190.1 \\
10 & - & 181.0 & - & 181.7 \\
11 & - & 133.8 & - & 135.5 \\
12 & - & 116.3 & - & 109.3 \\
13 & - & 114.2 & - & 113.7 \\
14 & - & 22.1 & $\mathrm{H}-\mathrm{Me} 2.50, \mathrm{~s}$ & 21.9 \\
$\mathrm{C}-\mathrm{Me}$ & $2.44, \mathrm{~s}$ & & & -2 \\
\hline
\end{tabular}


Compound-2 (0.38 g) was isolated as an orange crystalline solid with $R_{f}$ value 0.58 using $70 \%$ petroleum ether in ethyl acetate. The ${ }^{1} \mathrm{H}-\mathrm{NMR}$ spectrum of the compound (SI6) shows the presence of four aromatic protons at $\delta_{H} 7.42,7.11$, 7.06 , and $6.55 \mathrm{ppm}$. It has also revealed the presence of one set of methyl protons at $\delta_{H} 2.50$ and two-hydroxyl protons at $\delta_{H} 11.96$ and 12.04 ppm.

Its ${ }^{13} \mathrm{C}-\mathrm{NMR}$ spectrum data shows (SI7) the presence of 15 carbon signals (Table 1 ). Among these carbons, there are four $\mathrm{CH}$ aromatic ring protons at $\delta C$ : C-2 (124.5), C-4 (121.0), C-5 (109.2) and C-7 (108.3) ppm, two-carbonyl carbons that attached to benzene ring at $\delta_{c} \mathrm{C}-9$ (190.1) and C-10 (181.7) ppm, three oxygenated carbons of the aromatic ring at $\delta C$ : C-1 (161.9), C6 (164.9), C-8 (166.0) and five quaternary carbons indicated at C-3 (149.7), C-11 (135.5), C12 (109.3), C-13 (113.7) and C-14 (133.2) ppm. The ${ }^{13} \mathrm{C}$ NMR spectrum also showed the presence of one methyl carbon at $\delta C$ of 21.9 and one methyl-substituted carbon observed at $\delta C$ 149.7(C-3). Furthermore, COSY (SI8), HMBC (SI9), and HSQC (SI10) spectrum correlation data have confirmed that the proposed compound structure was named as 3-methyl-1,6,8trihydroxyanthraquinone (Emodin)(23-25) (Table 2, Figure 1). Emodin is found in Rhamnus and Rumex of higher plant species, and it is a metabolite of some Penicillium species $(12,24,26)$.

From Table 2 above (compound $\mathbf{1}$ ), the COSY correlation spectrum data show that there are three pairs of couplings between partner protons of $3 \mathrm{~J}$ value observed at $7.72(\mathrm{H}-5)$ with $\mathrm{H}-6$ (7.82), and $\mathrm{H}-6$ (7.82) with $\mathrm{H}-7$ (7.39) including the weak meta-coupled protons of ${ }^{4} \mathrm{~J}$ value of $\mathrm{H}-5$ coupling with $\mathrm{H}-7$. Similarly, a triplet proton for $\mathrm{H}-6$, and a doublet of doublet for its partners. The other important heteronuclear multiple bonds correlation spectrum is HSQC, which correlates the carbonproton of a single bond $\left({ }^{1} \mathrm{~J}\right)$. For instance, the correlation of $\mathrm{H}-2$ (7.22) with $\mathrm{C}-2$ (124.6), $\mathrm{H}-4$ (7.55) with C-4 (120.0), H-5 (7.72) with C-5
(119.8), and $\mathrm{H}-6$ (7.82) with $\mathrm{C}-6$ (137.8). On the other hand, the HMBC spectrum shows the correlation of protons with carbon in two to four bond distances. For example, it is observed that at proton $\delta \mathrm{H}: \mathrm{H}-2 \quad(7.22)$ correlated with $\mathrm{C}-11$ (133.8), C-4 (120.0), and the correlation with C-1 (161.8). The correlation at $\delta \mathrm{H}-4$ (7.55) showed a long-range correlation with C-10 (181.0), C-2 (124.6), and C-13 (114.2). Based on the combined spectroscopic data, the structure of compound $\mathbf{1}$ was proposed as Chrysophanol in Figure 1.

From Table 2 above (compound 2), HMBC spectrum showed the correlations of protons $\mathrm{H}-2$ (7.11) with C-1 (161.9), C-4 (121.0) C-11 (135.5) and $\mathrm{C}-\mathrm{Me}$ (21.9) and $\mathrm{H}-4$ (7.42) to $\mathrm{C}-1$ (161.9), C4 (121.0) C-13 (113.7) C-9 (190.1) and C-Me (21.9). These correlations give us the information of the partial aromatic structure of compound-2 indicated as ring A. Correspondingly, the correlations of protons $\mathrm{H}-5$ (7.06 ppm) to C-6 (164.9), C-9 (190.1), C-12 (109.3) and H-7 (6.55) to C-5 (109.2), C-8 (166.0) give us the presence of another partial aromatic cyclic structure of ring C.

The correlation of $\mathrm{H}-7$ with $\mathrm{C}-8$ and $\mathrm{C}-6$ indicates the presence of two alcohols in this meta position of the aromatic cycle. The correlations of $\mathrm{H}-5$ to the carbonyl signal $\mathrm{C}-10$ and of $\mathrm{H}-2$ (7.11 ppm) to carbonyl signal C-9 confirm the presence of anthraquinone. Moreover, the correlation of $\mathrm{H}-5$ to C-6 (an oxygenated quaternary carbon) indicates the presence of an alcohol group (Figure 2). And the COSY correlation spectrum $\left({ }^{1} H^{-1} H\right)$ helps to indicate the partner protons coupling each other like the two meta- coupling protons $\mathrm{H}-2$ with $\mathrm{H}-4$ (ring $\mathrm{A}$ ) and $\mathrm{H}-5$ with $\mathrm{H}-7$ (ring $\mathrm{C}$ ). Equally, the single bond coupling of the HSQC correlation spectrum $\left({ }^{1} \mathrm{H}-{ }^{13} \mathrm{C}\right)$ plays a vital role in suggestıng the structure of the compound. The HSQC correlation of the aromatic ring $\mathrm{A}$ of $\mathrm{H}-2$ to $\mathrm{C}-2$ and $\mathrm{H}-4$ to $\mathrm{C}-4$ equivalently for ring $\mathrm{B}, \mathrm{H}-5$ correlated to $\mathrm{C}-5$ and $\mathrm{H}-7$ to $\mathrm{C}-7$, which helps to propose the skeleton of the compound. Based on the combined NMR spectrum, compound $\mathbf{2}$ was proposed as Emodin. 


\section{Antibacterial and Antifungal Activity Evaluation}

The in vitro antibacterial and antifungal activities of crude extracts and isolated compounds ( $\mathbf{1}$ and $\mathbf{2}$ ) were carried out using four human pathogenic bacterial strains: $P$. aeruginosa, $K$. pneumonia, $S$. aureus, and $E$. coli and two fungal strains: $C$. albicans and $S$. cerevisiae by using agar disc diffusion method. The bioassay test was conducted using the petroleum ether, chloroform, acetone, and methanol extracts of $R$. abyssinicus roots. Its crude extracts have demonstrated a good yield of the antimicrobial zone of growth inhibition (SI11), but petroleum ether extract is not active against $S$. aureus and $K$. pneumoniae. The previous research report finding shows that the n-hexane extract of leaves, shoots, and roots of Rumex dentatus did not show any activity against several bacterial strains tested and the methanol extract has no prominent inhibition against fungal strains (27). Therefore, based on its promising antimicrobial activity in demonstrating a better zone of growth inhibition, good TLC profile, and a high percentage yield, the acetone extract was selected for the isolation of pure compounds. It has demonstrated zone of growth inhibition against $S$. aureus $21.0 \pm 1.4, K$. pneumoniae $15.5 \pm 0.4, P$. aeruginosa $22.5 \pm 0.7$, and $E$. coli $18.0 \pm 0.4 \mathrm{~mm}$ and the positive standard (Gentamicin) has $34.5 \pm 0.7$, $30.0 \pm 0.7$, 30.0 0.1 , and $32.0 \pm 0.1 \mathrm{~mm}$, respectively (Table 3 ). The previous report also indicated that $R$. abyssinicus is used for wound healing purposes in Ethiopia (12).

The pure compound-1 (Chrysophanol) and compound-2 (Emodin) have also exhibited a diameter of better zone of growth inhibition against $S$. aureus $(23.0 \pm 0.1 \mathrm{~mm})$ and $K$. pneumoniae $(22.5 \pm 0.4 \mathrm{~mm})$ than $P$. aeruginosa $(18.0 \pm 0.2 \mathrm{~mm})$ and $E$. coli $(18.0 \pm 0.4)$ in $\mathrm{mm}$ and the positive standard (Gentamicin) has 26.0 \pm 0.3 $\mathrm{mm}$ zone of growth inhibition (SI11). Compound$\mathbf{2}$ has also shown a better zone of growth inhibition against $K$. pneumoniae $(20.0 \pm 0.7)$ and $S$. aureus $(20.0 \pm 0.2)$ than $p$. aeruginosa $(19.0 \pm 0.3)$ and $E$. coli $(17.0 \pm 0.7)$ in $\mathrm{mm}$. The results indicated that compounds $\mathbf{1}$ and $\mathbf{2}$ have shown better antibacterial activity against $K$. pneumoniae and $S$. aureus strains and their activity was close to the positive standard (Gentamicin). These anthraquinones themselves have little therapeutic activity and need to be in the form of watersoluble glycosides to exert their action (26). Similarly, the antifungal activity of compounds 1 and 2 (SI12), was active over C. albicans with a zone of inhibition $20.0 \pm 0.4$ and $22.0 \pm 0.7 \mathrm{~mm}$, respectively which is almost equal to the zone of inhibition exhibited by the positive standard (Mancozeb). Conversely, both compounds $\mathbf{1}$ and $\mathbf{2}$ were not active on the $S$. cerevisiae fungal strains (Table 3). Thus far, it was reported that chrysophanol (1) and emodin (2) are antimicrobial and wound healing active constituents isolated from the rhizomes of $R$.abyssinicus and other plant species $(12,28)$.

\section{CONCLUSION}

The main objective of this study was to carry out a phytochemical constituent investigation and in vitro antimicrobial activity screening of the root extracts of $R$. abyssinicus. Based on its promising bioactivity and good TLC profile, the acetone crude extract was subjected to column chromatographic isolation packed with silica gel using petroleum ether. As a result, from the root extracts of $R$. abyssinicus, two compounds, Chrysophanol (Compound 1) and Emodin (Compound 2) anthraquinones were isolated and evaluated against four bacterial and two fungal strains. It was screened against $S$. aureus, $P$. aeruginosa, $E$. coli, K. pneumoniae, C. albicans, and $S$. cerevisiae using Gentamycin and Mancozeb as positive standards, and DMSO as negative standard. The antibacterial activity of isolated compound $\mathbf{1}$ showed higher activity against $S$. aureus $22.5 \pm 0.4$ $\mathrm{mm}, P$. aeruginosa $18.0 \pm 0.2 \mathrm{~mm}, E$. coli $18.0 \pm 0.4$ $\mathrm{mm}, K$. pneumoniae $23.0 \pm 0.1 \mathrm{~mm}$ than 2; while antifungal activity $\mathbf{2}$ is higher than $C$. albicans $22 \pm 0.7 \mathrm{~mm}$ than 1 for C. albicans $20 \pm 0.4 \mathrm{~mm}$. On the contrary, compound $\mathbf{2}$ was not actıve against the $S$. cerevisiae strain. And the structures of these compounds were elucidated using 1D and 2D-NMR spectroscopic techniques. 


\begin{tabular}{|c|c|c|c|c|c|}
\hline & $\begin{array}{l}\text { Position } \\
\text { JC }\end{array}$ & $\begin{array}{c}\text { Compound } 1 \\
\boldsymbol{\delta} \mathbf{H}\end{array}$ & HSQC $\left({ }^{1} \mathrm{~J}\right)$ & $\cos Y(3 J, 4 J)$ & HMBC $\left({ }^{3} J\right)$ \\
\hline 2 & 124.6 & $\mathrm{H}-2(7.22)$ & $\mathrm{C}-\mathrm{C}-2 \longleftrightarrow \mathrm{H}-2$ & - & $\mathrm{H}-2 \rightarrow \mathrm{C}-4, \mathrm{C}-11$ \\
\hline 4 & 120.0 & $\mathrm{H}-4(7.55)$ & $\mathrm{C}-4 \longleftrightarrow \mathrm{H}-4$ & $5 e^{-}$ & $\mathrm{H}-4 \rightarrow \mathrm{C}-2, \mathrm{C}-10$ \\
\hline 5 & 119.8 & $\mathrm{H}-5$ (7.72) & $\mathrm{C}-5 \longleftrightarrow \mathrm{H}-5$ & $\mathrm{H}-5 \longleftrightarrow \mathrm{H}-6$ & $\mathrm{H}-5 \rightarrow \mathrm{C}-10, \mathrm{C}-7, \mathrm{C} 13$ \\
\hline 6 & 137.8 & $\mathrm{H}-6(7.82)$ & $\mathrm{C}-6 \longleftrightarrow \mathrm{H}-6$ & $\mathrm{H}-5 \longleftrightarrow \mathrm{H}-7$ & $\mathrm{H}-6 \rightarrow \mathrm{C} 14, \mathrm{C}-8$ \\
\hline \multirow[t]{2}{*}{$\mathrm{Me}$} & $\begin{array}{l}124.9 \\
22.1\end{array}$ & $\begin{array}{l}\mathrm{H}-7(7.39) \\
\mathrm{H}-\mathrm{Me}(2.44)\end{array}$ & $\begin{array}{l}\mathrm{C}-7 \longleftrightarrow \mathrm{H}-7 \\
-\end{array}$ & $\mathrm{H}-6 \stackrel{\mathrm{H}-7}{\longleftrightarrow}$ & $\begin{array}{l}\mathrm{H}-7 \rightarrow \mathrm{C}-5, \mathrm{C}-13 \\
\mathrm{H}-\mathrm{Me} \rightarrow \mathrm{C}-2, \mathrm{C}-4\end{array}$ \\
\hline & Compound-2 & & & & \\
\hline 2 & 124.5 & $\mathrm{H}-2(7.11)$ & $\mathrm{H}-2 \longleftrightarrow \mathrm{C}-2$ & - & $\mathrm{H}-2 \rightarrow \mathrm{C}-4, \mathrm{C}-13$ \\
\hline $\begin{array}{l}4 \\
5\end{array}$ & $\begin{array}{l}121.0 \\
109.2\end{array}$ & $\begin{array}{l}\mathrm{H}-4(7.42) \\
\mathrm{H}-5(7.06)\end{array}$ & $\begin{array}{l}\mathrm{H}-4 \longleftrightarrow \mathrm{C}-4 \\
\mathrm{H}-5 \longleftrightarrow \mathrm{C}-5\end{array}$ & $\begin{array}{l}- \\
-\end{array}$ & $\begin{array}{l}\mathrm{H}-4 \rightarrow \mathrm{C}-2, \mathrm{C}-10, \mathrm{C}-13 \\
\mathrm{H}-5 \rightarrow \mathrm{C}-7, \mathrm{C}-10, \mathrm{C}-12\end{array}$ \\
\hline 7 & 108.3 & $H-7(6.55)$ & $\mathrm{H}-7 \longleftrightarrow \mathrm{C}-7$ & - & $\mathrm{H}-7 \rightarrow \mathrm{C}-5, \mathrm{C}-12$ \\
\hline 8 & 166.0 & $\mathrm{H}-8(12.04)$ & $\mathrm{OH}-8 \longleftrightarrow \mathrm{C}-8$ & - & - \\
\hline $\mathrm{Me}$ & 21.9 & $\mathrm{H}-\mathrm{Me}(2.50)$ & $\mathrm{H}-\mathrm{Me} \longleftrightarrow \mathrm{C}-\mathrm{Me}$ & - & $\mathrm{H}-\mathrm{Me} \rightarrow \mathrm{C}-2, \mathrm{C}-4$ \\
\hline
\end{tabular}
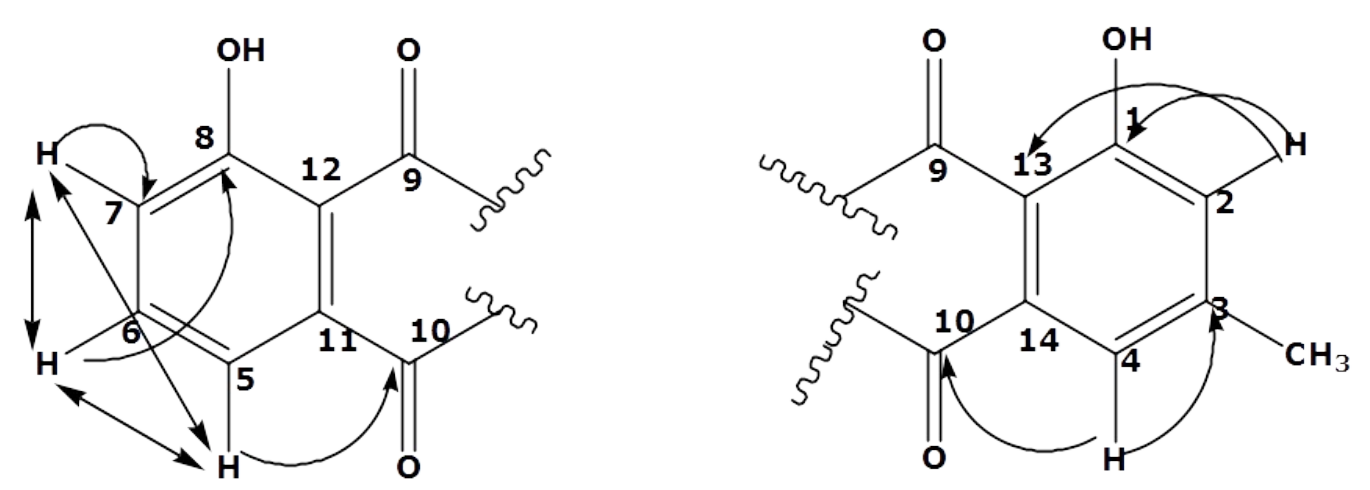

Figure 2. COSY, HSQC, and HMBC correlations of the aromatic cycle A, B, and C. 
Table 3. In-vitro Antimicrobial Activities of Extracts and Isolated Compounds from Roots of R. abyssinicus in mm.

\begin{tabular}{|c|c|c|c|c|c|c|c|c|}
\hline \multirow[t]{2}{*}{ Bacterial strain } & \multicolumn{4}{|c|}{ The diameter of zone of inhibition in $\mathrm{mm}(\mathrm{M} \pm \mathrm{SD})$} & \multirow[t]{2}{*}{ Gentamycin } & \multirow[t]{2}{*}{ DMSO } & \multicolumn{2}{|c|}{ Isolated compounds } \\
\hline & $\mathrm{PE}$ & $\mathrm{CE}$ & $\mathrm{AE}$ & ME & & & $\mathrm{C}-1$ & C-2 \\
\hline S. aureus & $9.5 \pm 0.7$ & $17.5 \pm 1.4$ & $21.0 \pm 1.4$ & $18.0 \pm 0.1$ & $34.5 \pm 0.7$ & NI & $23.0 \pm 0.1$ & $20.0 \pm 0.2$ \\
\hline$P$. aeruginosa & NA & $12.5 \pm 0.7$ & $15.5 \pm 0.4$ & $13.0 \pm 0.1$ & $30.5 \pm 0.7$ & NI & $18.0 \pm 0.2$ & $19.0 \pm 0.3$ \\
\hline E. coli & $10.5 \pm 0.7$ & $14.0 \pm 0.2$ & $18.0 \pm 0.4$ & $13.5 \pm 0.7$ & $32.0 \pm 0.1$ & NI & $18.0 \pm 0.4$ & $17.0 \pm 0.7$ \\
\hline K. pneumoniae & NA & $11.5 \pm 0.7$ & $22.5 \pm 0.7$ & $15.0 \pm 0.2$ & $30.0 \pm 0.1$ & NI & $22.5 \pm 0.4$ & $20.0 \pm 0.7$ \\
\hline Gentamycin & - & - & - & - & - & - & $26.0 \pm 0.3$ & $26.0 \pm 0.2$ \\
\hline DMSO & - & - & - & - & - & - & NI & $\mathrm{NI}$ \\
\hline Fungal strain & & & & & Mancozeb & & $\mathrm{C}-1$ & C-2 \\
\hline C. albicans & $9.0 \pm 1.4$ & $12.0 \pm 0.1$ & $17.5 \pm 0.7$ & $13.0 \pm 3$ & $20.5 \pm .07$ & NI & $20.0 \pm 0.4$ & $22.0 \pm 0.7$ \\
\hline S. cerevisiae & $7.5 \pm 0.7$ & $10.0 \pm 0.7$ & $15.0 \pm 0.7$ & $15.0 \pm 1.4$ & $24.5 \pm 0.7$ & NI & NA & NA \\
\hline Mancozeb & - & - & - & - & - & - & $22.0 \pm 0.1$ & $22.0 \pm 0.2$ \\
\hline DMSO & - & - & - & - & - & - & NI & NI \\
\hline
\end{tabular}

\section{Key :}

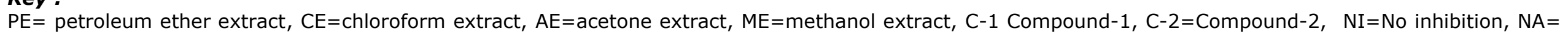
Not active, $\mathrm{DMSO}=$ Dimethyl sulfoxide, $\mathrm{M} \pm \mathrm{SD}=$ Mean \pm Standard Deviation 


\section{ACKNOWLEDGMENTS}

The authors wish to thank Jimma University, College of Natural Sciences for funding, and the Department of Biology for hosting us during the bioassay tests and professional support. We are also thankful to Dr. Kibrom Gebreheiwot, Institute of Environmental Research (INFU), TU Dortmund, Germany, for running the NMR data of the compounds.

\section{REFERENCES}

1. Moges A. Ethiopian Common Medicinal Plants: Their Parts and Uses in Traditional Medicine Ecology and Quality Control. In: Sağlam YME-AGEMRE-NG, editor. Rijeka: IntechOpen; 2020. p. Ch. 7. Available from:

https://doi.org/10.5772/intechopen.86202

2. Cavalcante IHL, Martins ABG. Charles Johnson, Tim Raiford \& Kristi Whitley. Int J Fruit Sci. 2005;5(4):39-46.

3. Abubakar MG, Yerima MB, Zahriya AG, Ukwuani AN. Acute toxicity and antifungal studies of ethanolic leaves, stem and pulp extract of Tamarindus indica. Res J Pharm Biol Chem Sci. 2010;1(4):104-11.

4. Yirga G. Use of traditional medicinal plants by indigenous people in mekele town, capital city of tigray regional state of Ethiopia. J Med Plants Res. 2010;4(17):1799-804.

5. Tesfahuneygn G, Gebreegziabher G. Medicinal Plants Used in Traditional Medicine by Ethiopians: A Review Article OPEN ACCESS. J Respir Med Lung Dis. $2019 ; 4(1): 1-3$.

6. Muluye AB, Ayicheh MW. Medicinal plants utilized for hepatic disorders in Ethiopian traditional medical practices: a review. Clin Phytoscience. 2020;6(1).

7. Yineger $H$, Yewhalaw D, Teketay D. Ethnomedicinal plant knowledge and practice of the Oromo ethnic group in southwestern Ethiopia. J Ethnobiol Ethnomed. 2008;4:1-10.

8. Ekalu A, Gbekele-Oluwa Ayo R, Habila JD, Hamisu I. Bioactivities of phaeophytin a, a-amyrin, and lupeol from Brachystelma togoense Schltr. J Turkish Chem Soc Sect A Chem. 2019;6(3):411-8.

9. Tesfaye S, Belete A, Engidawork E, Gedif T, Asres K. Ethnobotanical Study of Medicinal Plants Used by Traditional Healers to Treat Cancer-Like Symptoms in Eleven Districts, Ethiopia. Evidencebased Complement Altern Med. 2020;2020.
10. Mekonnen T, Urga K, Engidawork E. Evaluation of the diuretic and analgesic activities of the rhizomes of Rumex abyssinicus Jacq in mice. J Ethnopharmacol. 2010;127(2):433-9.

11. Mohammed SA, Madhan B, Demissie BA, Velappan B, Tamil Selvi A. Rumex abyssinicus (mekmeko) Ethiopian plant material for preservation of goat skins: Approach for cleaner leather manufacture. J Clean Prod [Internet]. 2016;133:1043-52. Available from: http://dx.doi.org/10.1016/j.jclepro.2016.06.043

12. Mulisa E, Asres K, Engidawork E. Evaluation of wound healing and anti-inflammatory activity of the rhizomes of Rumex abyssinicus J.

(Polygonaceae) in mice. BMC Complement Altern Med [Internet]. 2015;15(1):1-10. Available from: http://dx.doi.org/10.1186/s12906-015-0878-y

13. Rouf ASS, Islam MS, Rahman MT. Evaluation of antidiarrhoeal activity Rumex maritimus root. J Ethnopharmacol. 2003;84(2-3):307-10.

14. Worku N, Mossie A, Stich A, Daugschies A, Trettner S, Hemdan NYA, et al. Evaluation of the In Vitro Efficacy of Artemisia annua, Rumex abyssinicus, and Catha edulis Forsk Extracts in Cancer and Trypanosoma brucei Cells . ISRN Biochem. 2013;2013:1-10.

15. Sharma RS, Mishra V, Singh R, Seth N, Babu CR. Antifungal activity of some Himalayan medicinal plants and cultivated ornamental species. Fitoterapia [Internet]. 2008;79(7-8):58991. Available from:

http://dx.doi.org/10.1016/j.fitote.2008.06.004

16. Getie M, Gebre-Mariam T, Rietz R, Höhne C, Huschka C, Schmidtke M, et al. Evaluation of the anti-microbial and anti-inflammatory activities of the medicinal plants Dodonaea viscosa, Rumex nervosus and Rumex abyssinicus. Fitoterapia. $2003 ; 74(1-2): 139-43$.

17. Kumar RS, Venkateshwar C, Samuel G, Rao SG. Phytochemical Screening of some compounds from plant leaf extracts of Holoptelea integrifolia ( Planch .) and Celestrus emarginata ( Grah .) used by Gondu tribes at Adilabad District. International Journal of Engineering Science Invention. $2013 ; 2(8): 65-70$.

18. Nithya Devi P, Kaleeswari S, Poonkothai M. Antimicrobial activity and phytochemical analysis of fruit extracts of Terminalia Bellerica. Int J Pharm Pharm Sci. 2014;6(5):639-42.

19. Abdissa D, Geleta G, Bacha K, Abdissa N. Phytochemical investigation of Aloe pulcherrima roots and evaluation for its antibacterial and 
antiplasmodial activities. PLoS One. 2017;12(3):110.

20. Mohammed SA, Panda RC, Madhan B, Demessie BA. Rumex abyssinicus (mekmeko) extract as cleaner approach for dyeing in product manufacture: Optimization and modeling studies. Asia-Pacific J Chem Eng. 2018;13(2):1-19.

21. Prateeksha, Yusuf MA, Singh BN, Sudheer S, Kharwar RN, Siddiqui S, et al. Chrysophanol: A natural anthraquinone with multifaceted biotherapeutic potential. Biomolecules. 2019;9(2):1-24.

22. Van Wyk BE, Yenesew A, Dagne E. Chemotaxonomic survey of anthraquinones and pre-anthraquinones in roots of Aloe species. Biochem Syst Ecol. 1995;23(3):267-75.

23. Gizachew A, Legesse A, Berhanu, M. A. Natural Product Communications: Editorial. Nat Prod Commun. 2010;5(5):747-50.

24. Augustin N, Nuthakki VK, Abdullaha M, Hassan
QP, Gandhi SG, Bharate SB. Discovery of Helminthosporin, an Anthraquinone Isolated from Rumex abyssinicus Jacq as a Dual Cholinesterase Inhibitor. ACS Omega. 2020;5(3):1616-24.

25. Zelalem GA, Dula DE. Isolation , Characterization and Antibacterial Activities Evaluation of Rumex abyssinicus Rootbark Extracts. Nat Prod Chem Res. 2019;7(1):1-8.

26. Dewick PM. Medicinal Natural Products: A Biosynthetic Approach. 3rd Edition. John Wiley \& Sons, Ltd. 2009. 1-546 p.

27. Fatima N, Zia M, Riaz-ur-Rehman, Rizvi ZF, Ahmad S, Mirza B, et al. Biological activities of Rumex dentatus L: Evaluation of methanol and hexane extracts. African J Biotechnol. 2009;8(24):6945-51.

28. Tabin S, Gupta RC, Bansal G, Kamili AN. Comparative HPLC analysis of emodin, aloe emodin and rhein in Rheum emodi of wild and in vitro raised plants. Journal of Pharmacognosy and Phytochemistry. 2016;5(2):121-30. 


\section{Supporting information}

"Chemical Constituents of Rumex abyssinicus Roots and Evaluation of Its Antimicrobial Activities" Muaz Shifa, Dele Abdissa, Tsegaye Girma Asere*

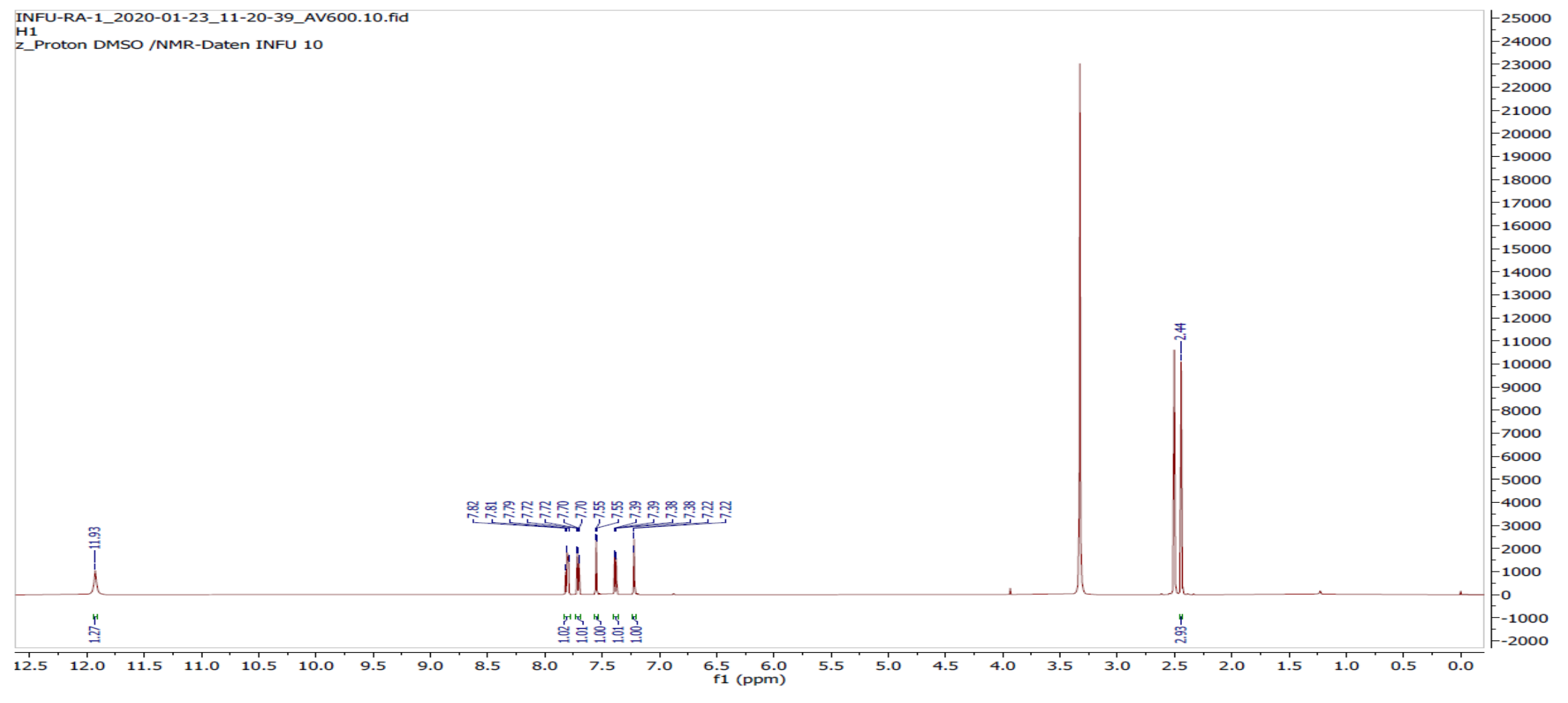

SI1a: ${ }^{1} \mathrm{H}-\mathrm{NMR}$ spectral data of compound-1. 


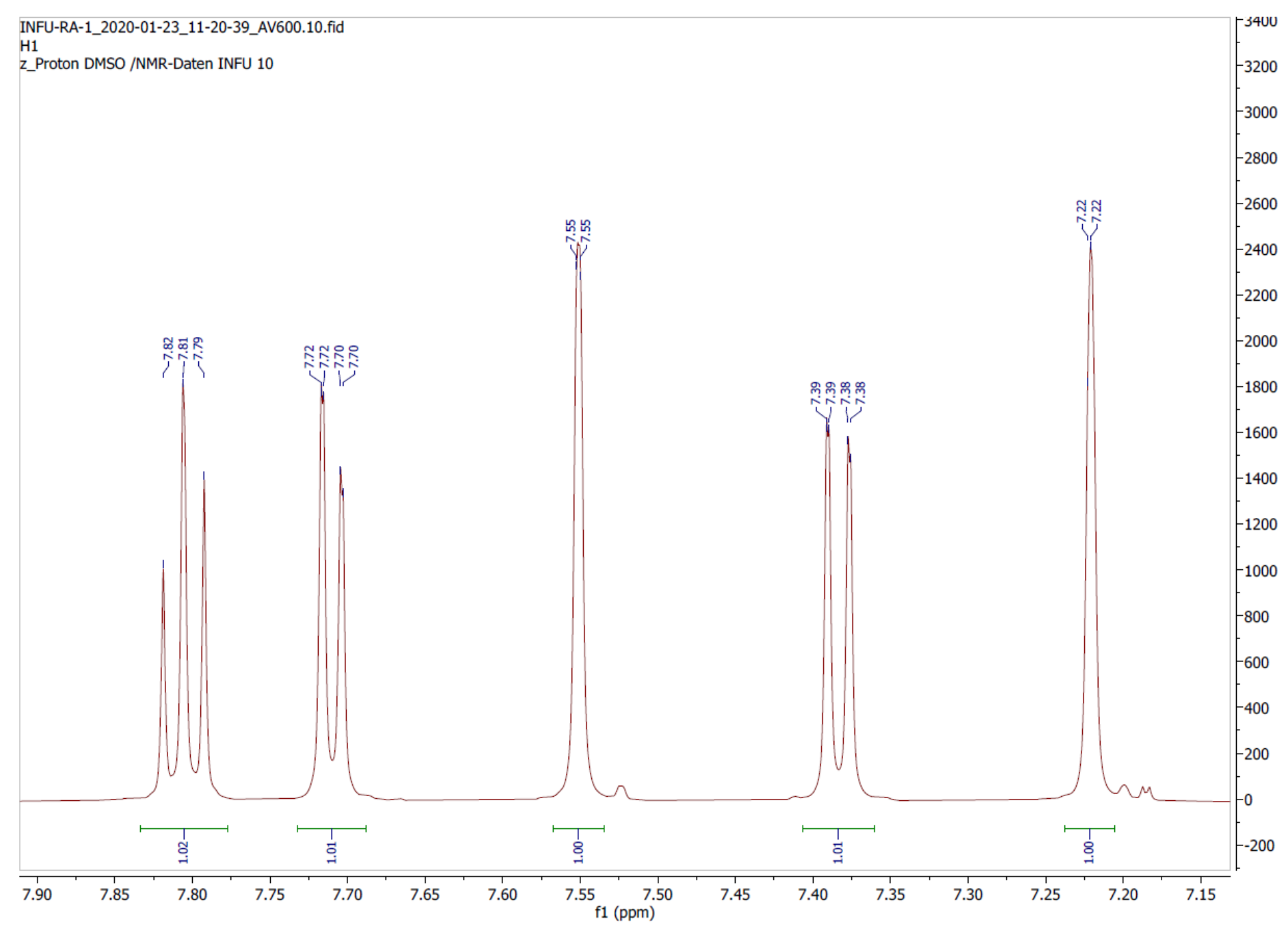

SI1b: Expanded ${ }^{1}$ HNMR spectral data of compound-1 from 7.15-7.90 ppm. 


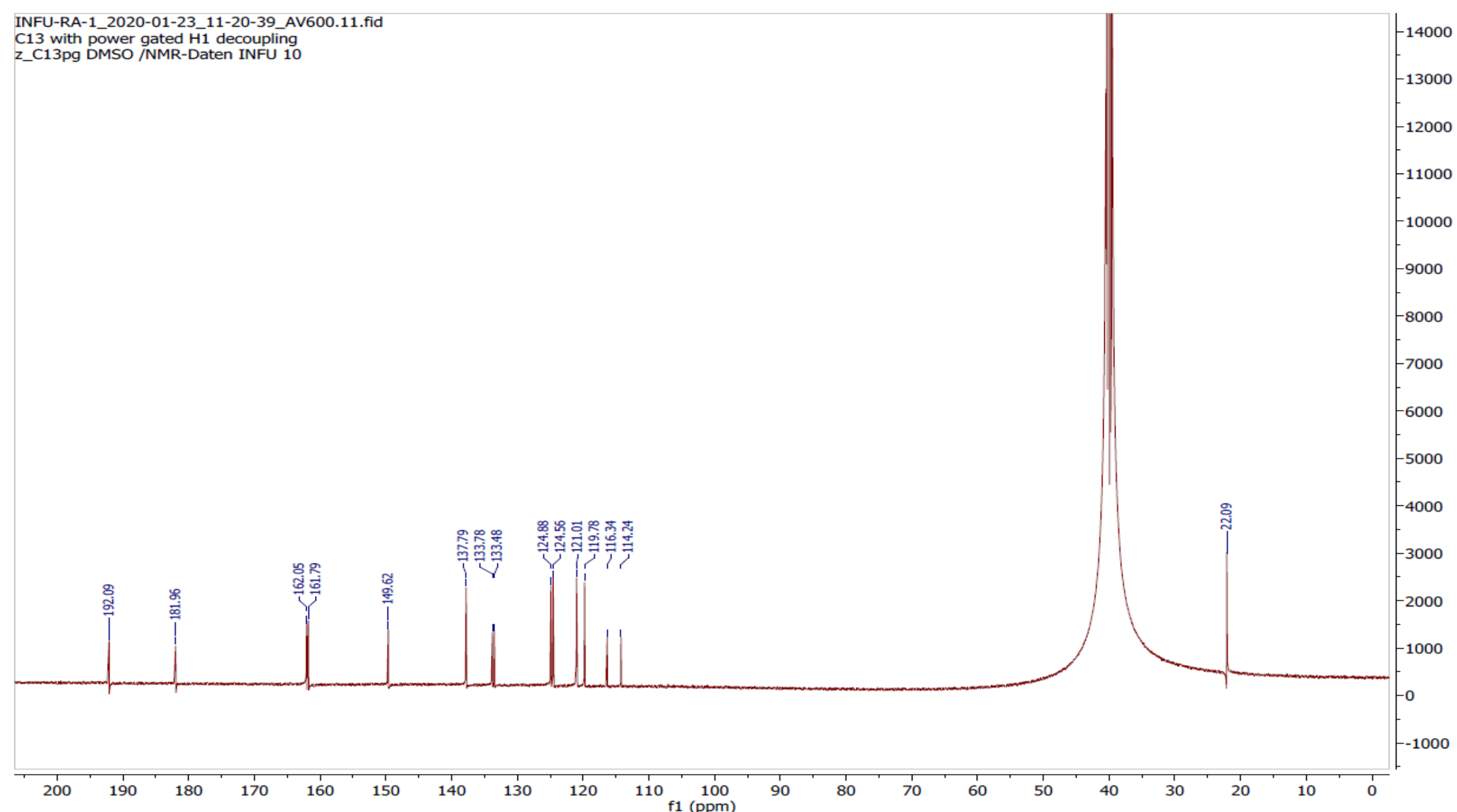

SI2a: ${ }^{13}$ CNMR spectral data of compound-1. 


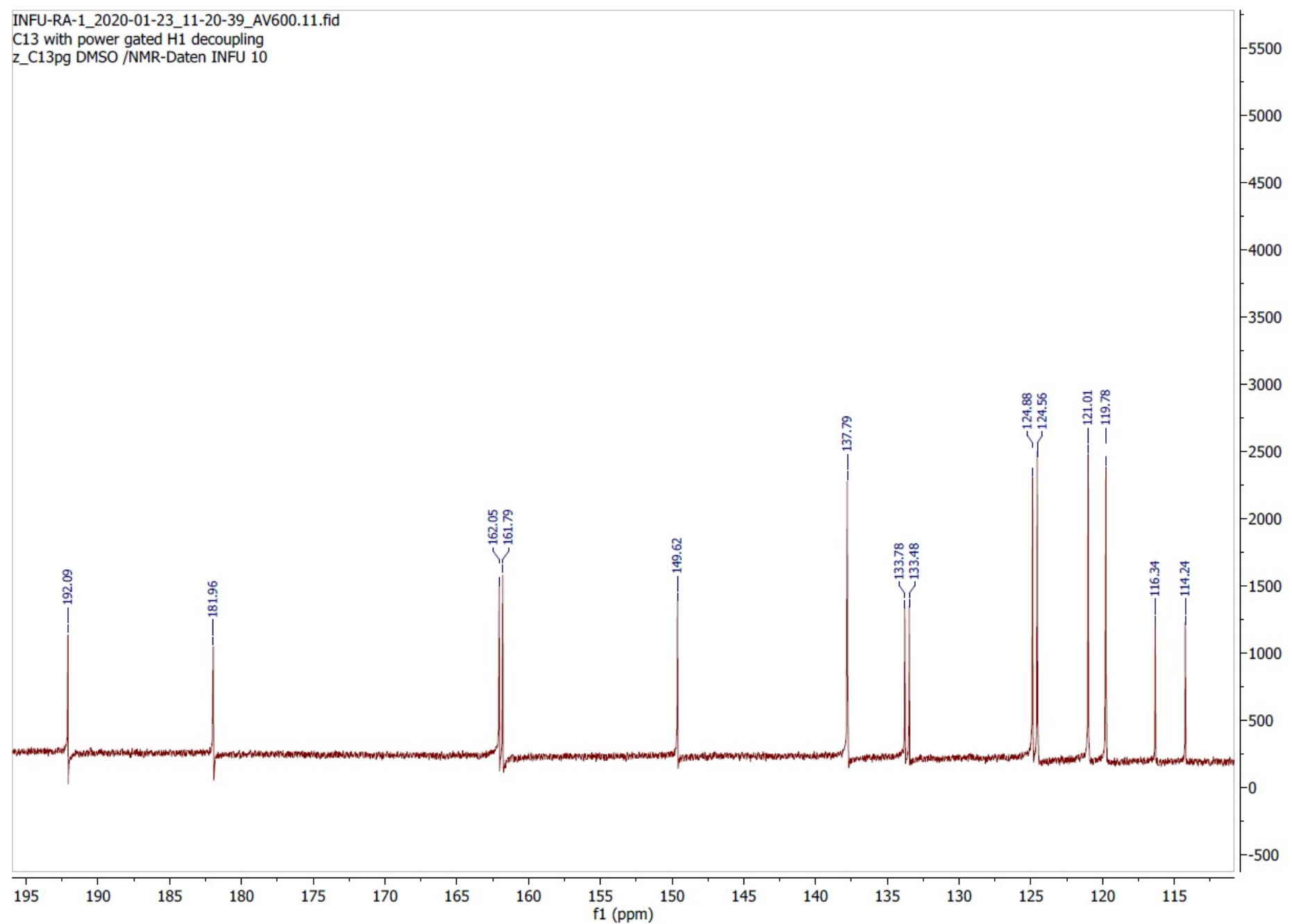

SI2b: Expanded ${ }^{13}$ CNMR spectral data of compound-1 from 115-195 ppm. 


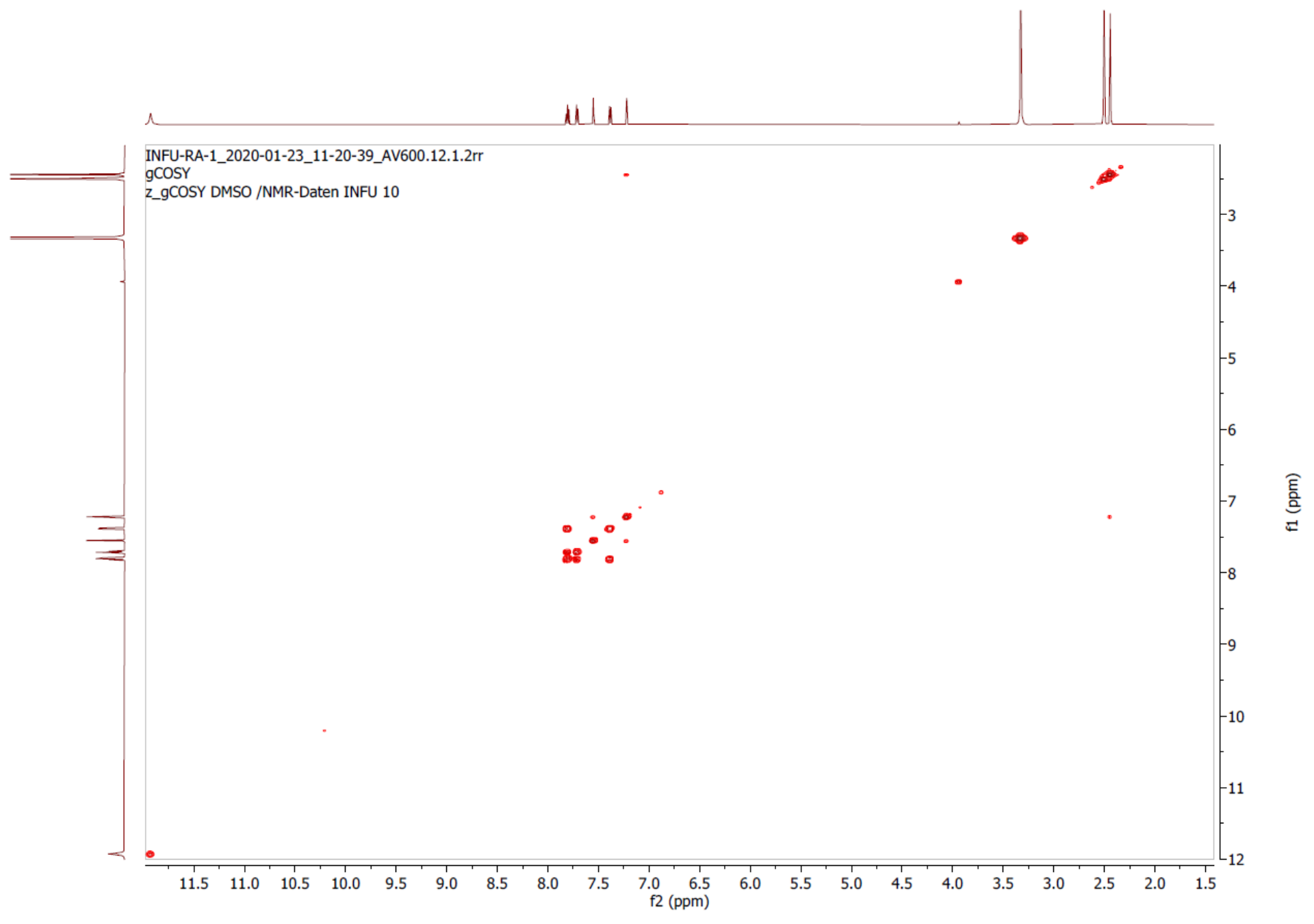

SI3: COSY spectral data of compound-1. 


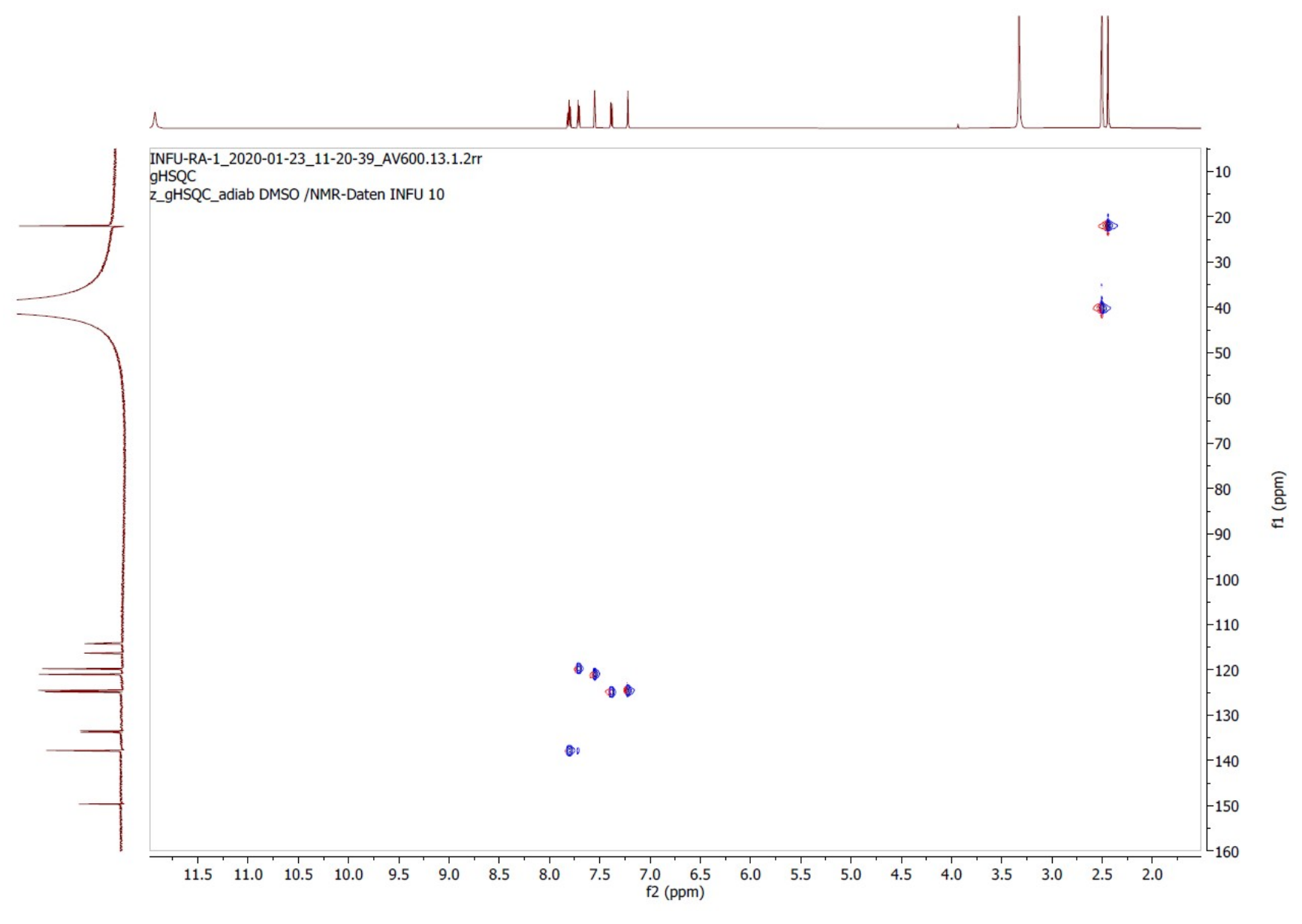

SI4: HSQC spectral data of compound-1. 


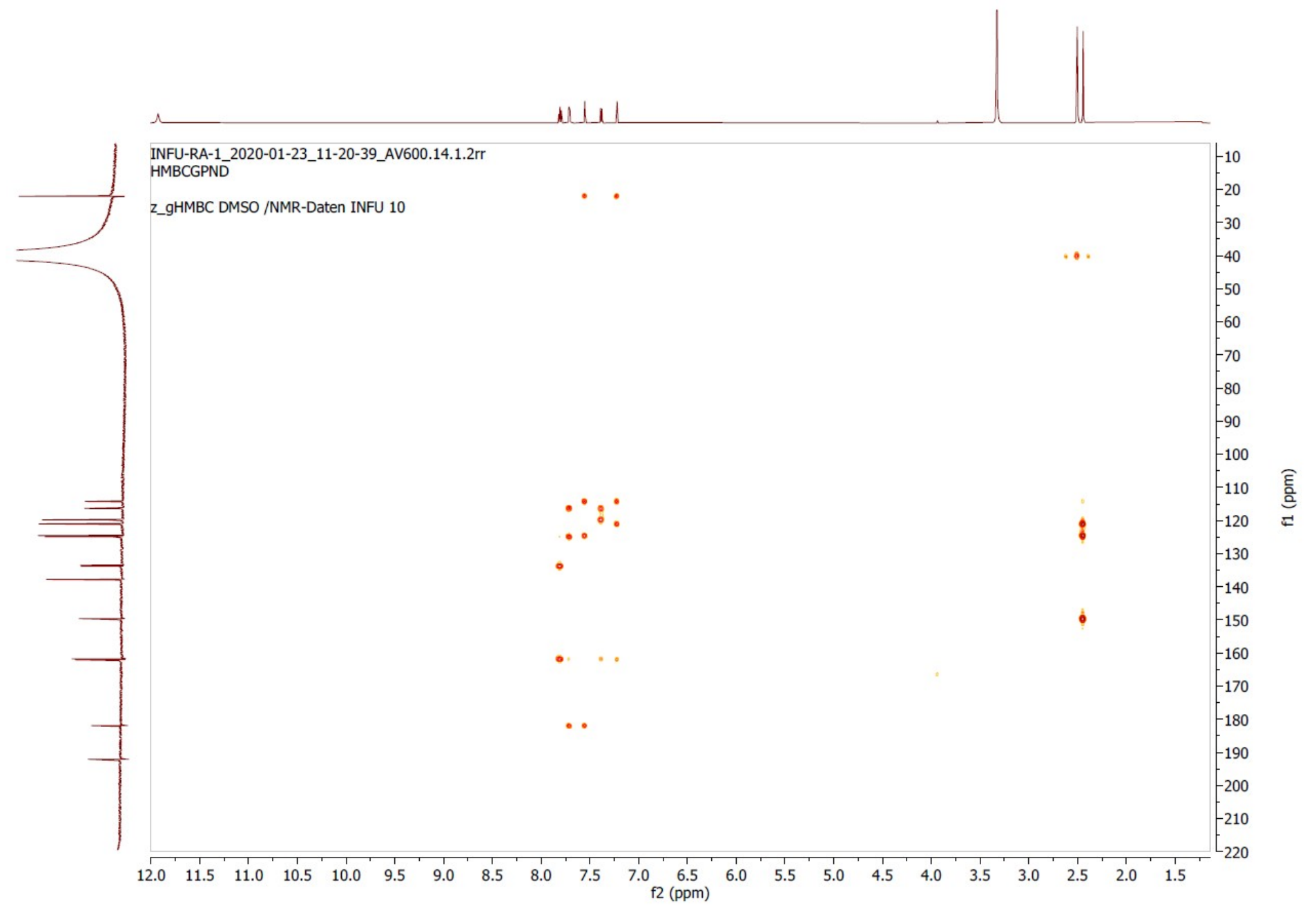

SI5: HMBC spectral data of compound-1. 


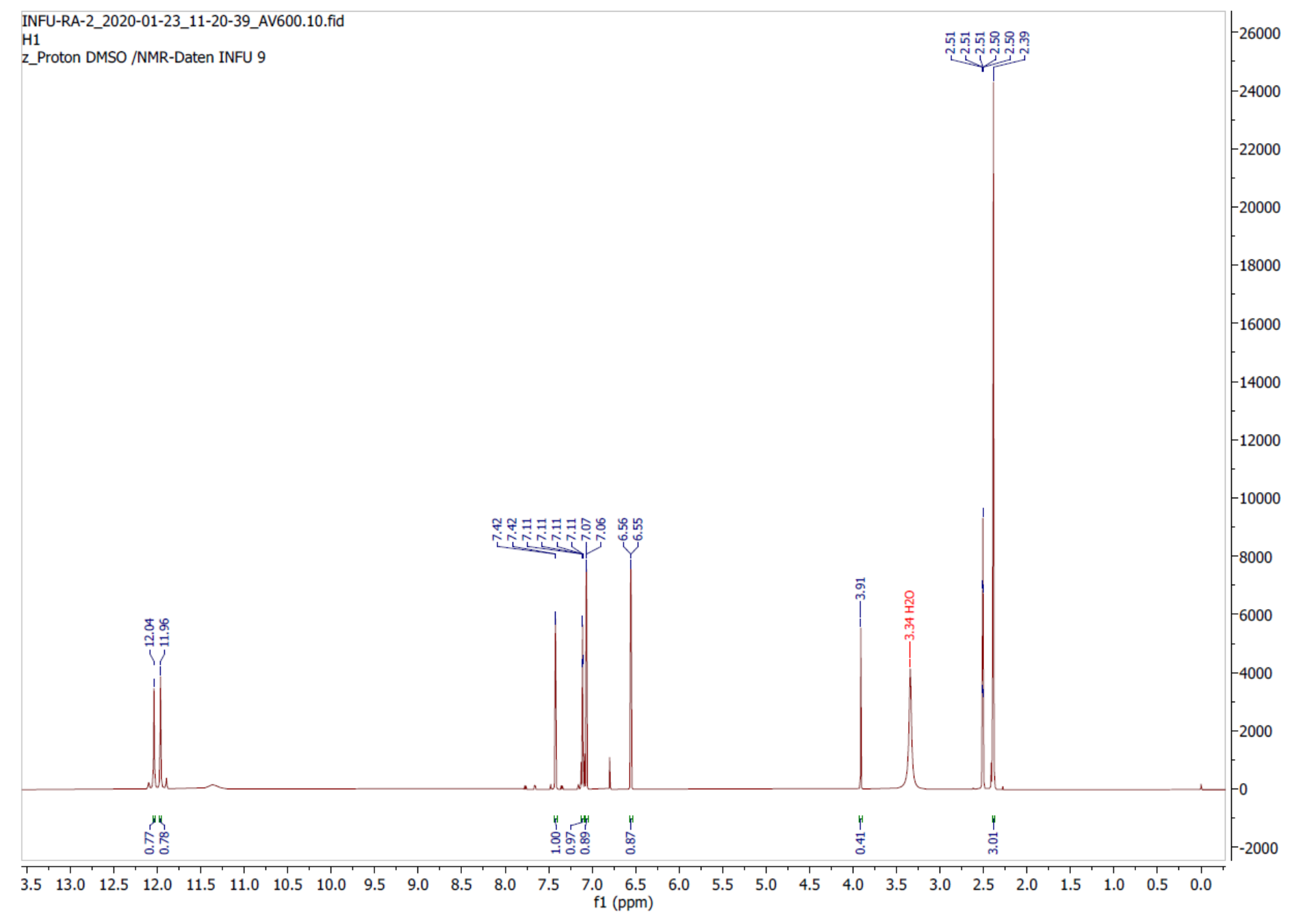

SI6a: ${ }^{1}$ HNMR spectral data of compound-2. 


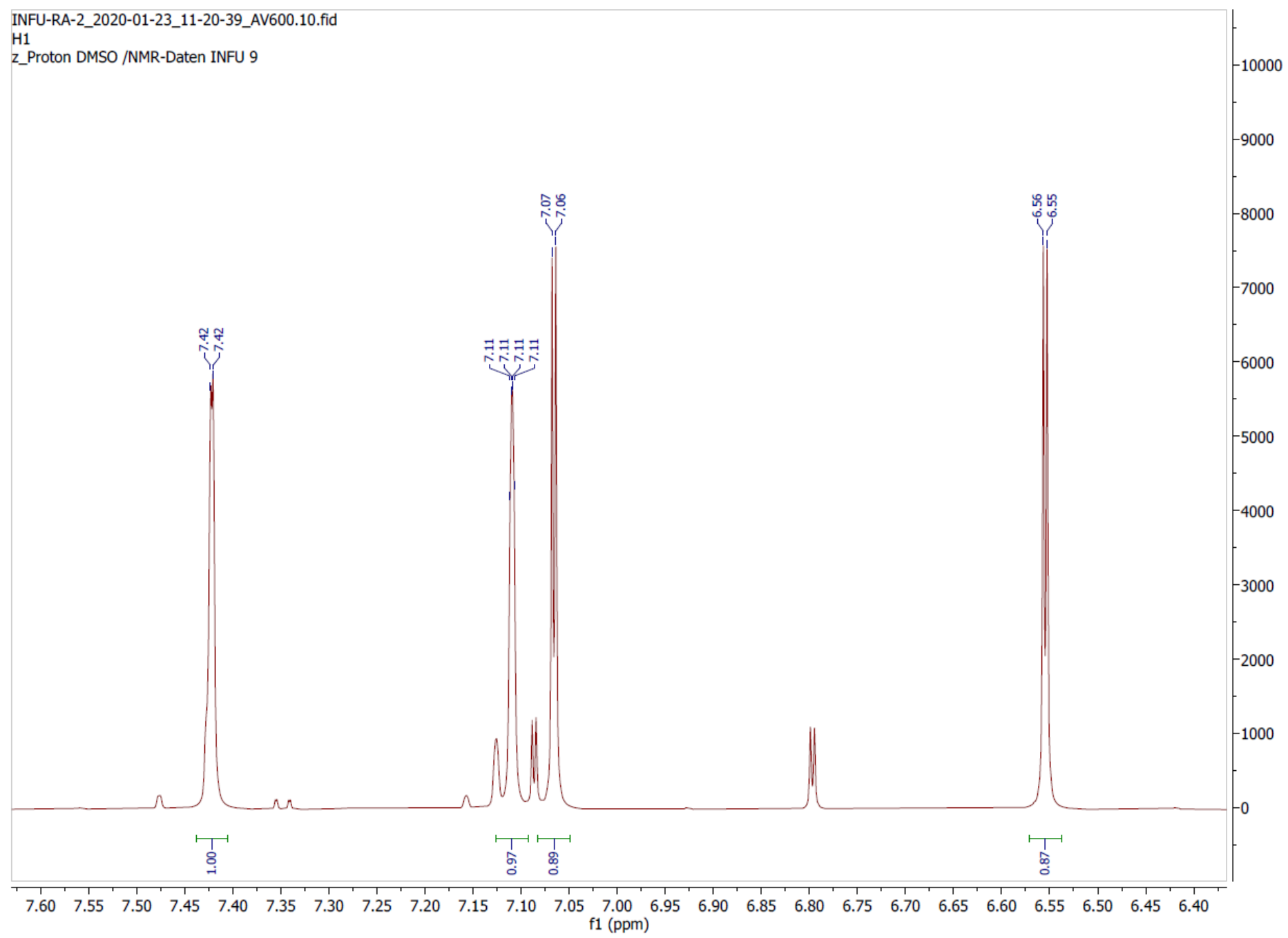

SI6b: Expanded ${ }^{1}$ HNMR spectral data of compound-2 from 6.40-7.60 ppm. 


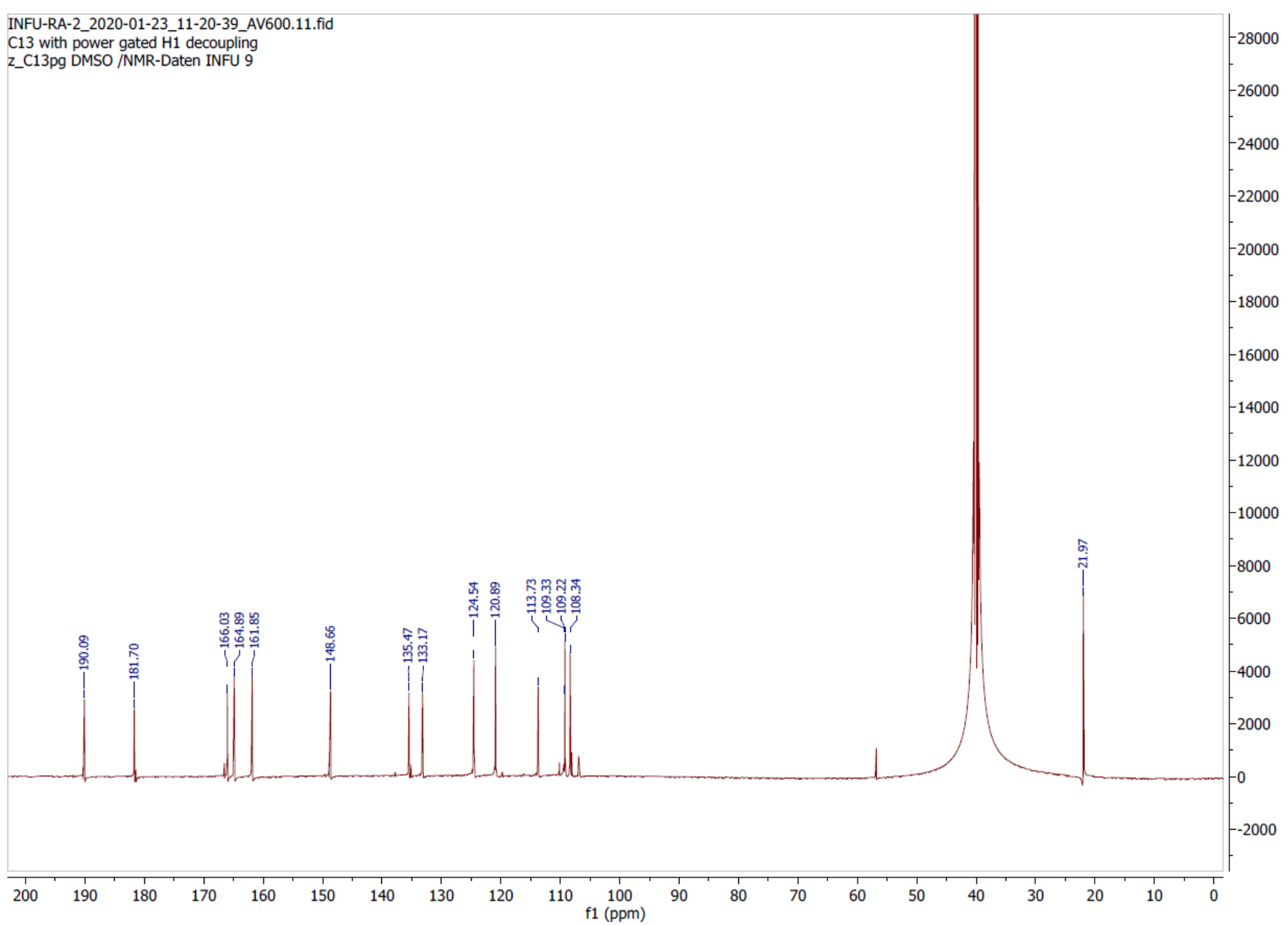

SI7a: ${ }^{13}$ CNMR spectral data of compound- 2 . 


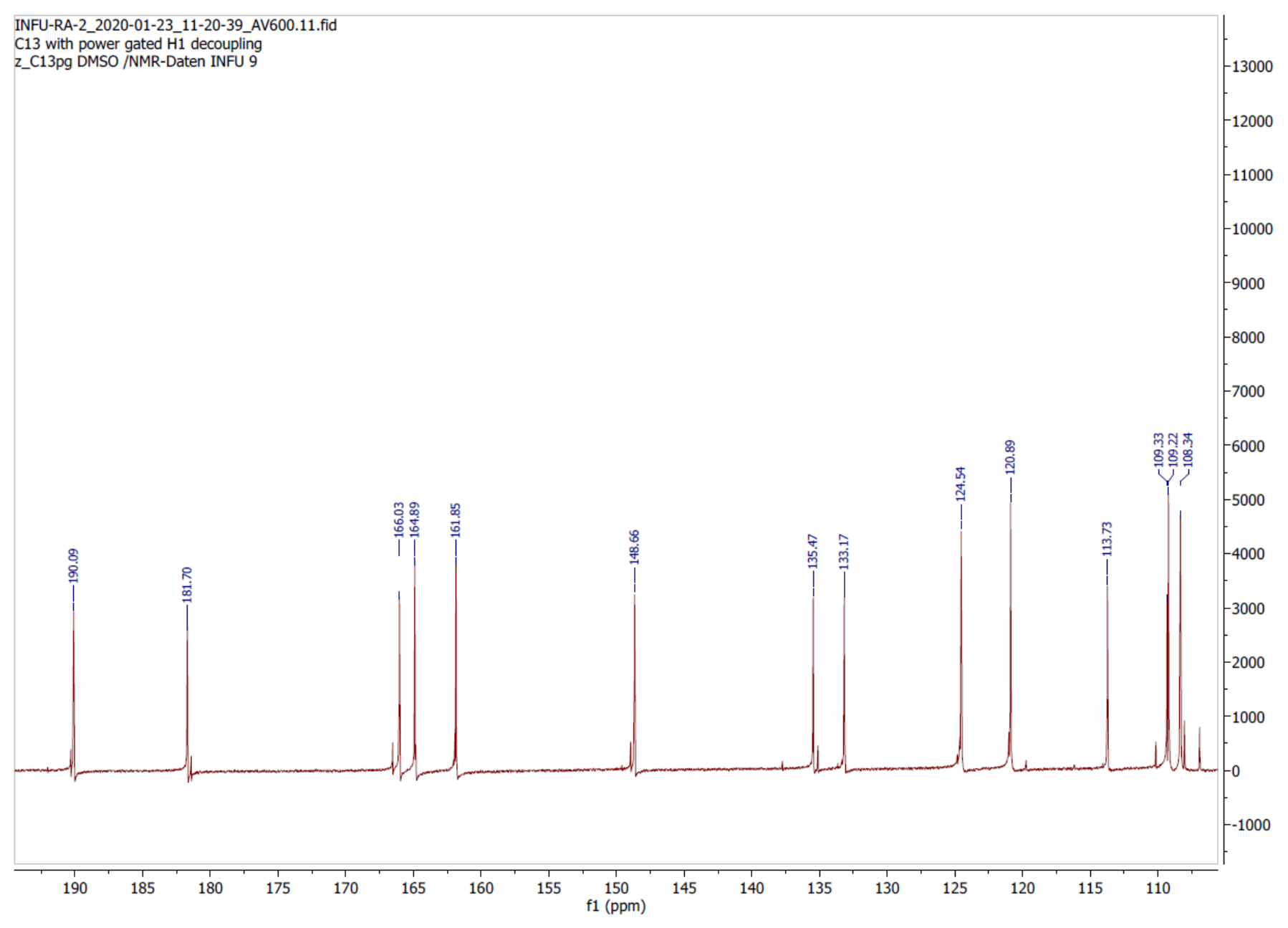

SI7b: Expanded ${ }^{13}$ CNMR spectral data of compound-2 from 110-190 ppm. 


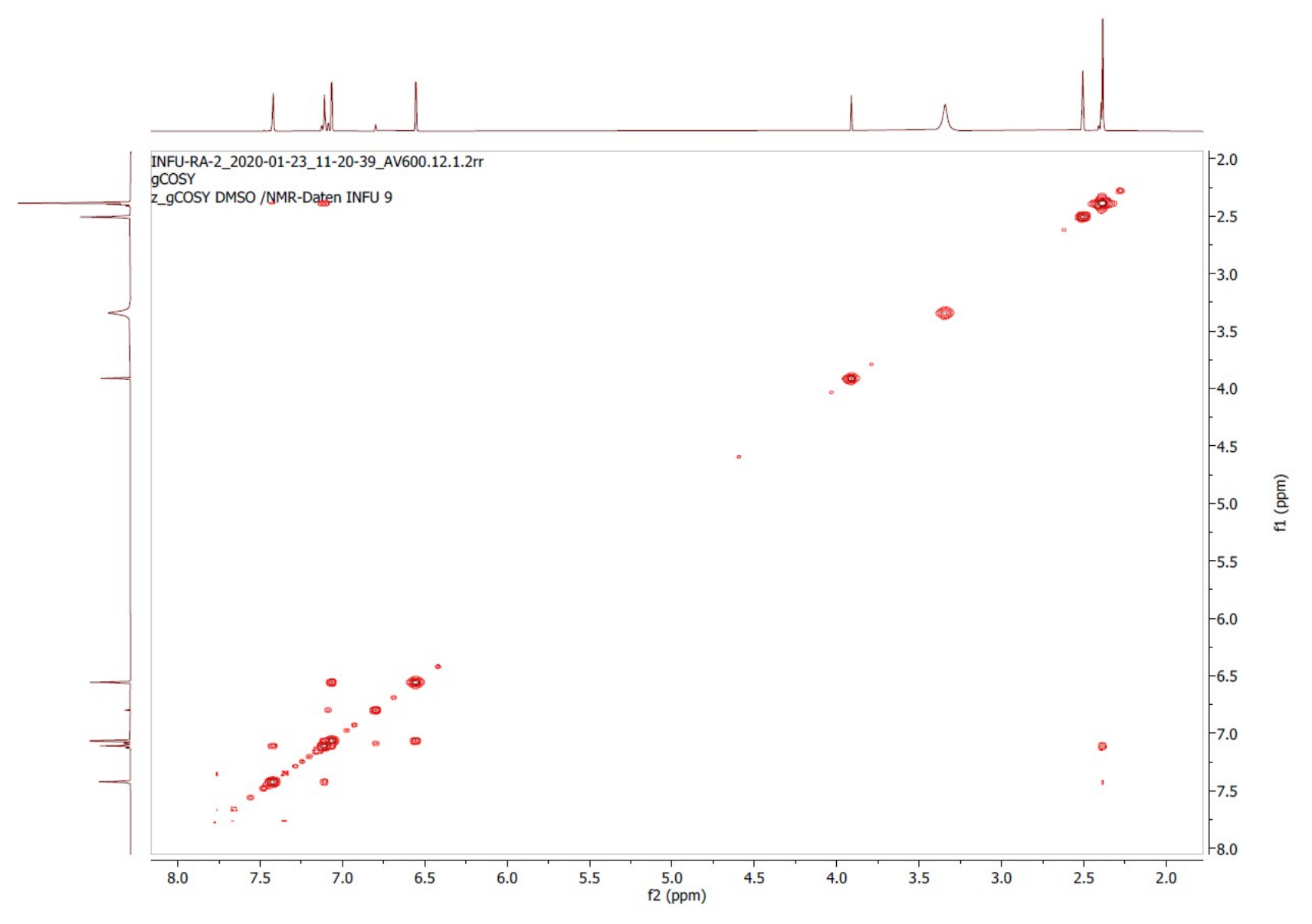

SI8: COSY spectral data of compound-2. 


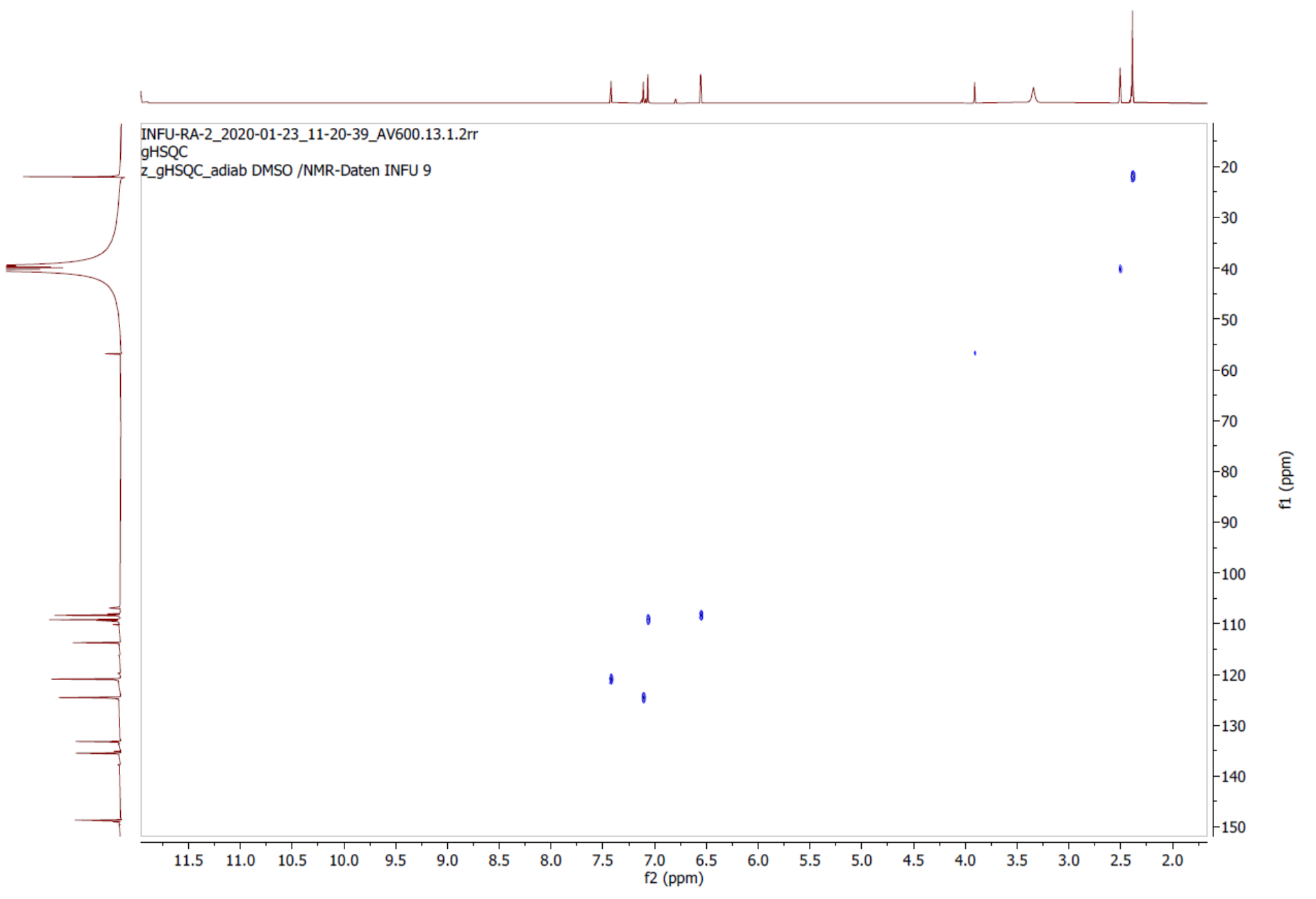

SI9: HSQC spectral data of compound-2. 


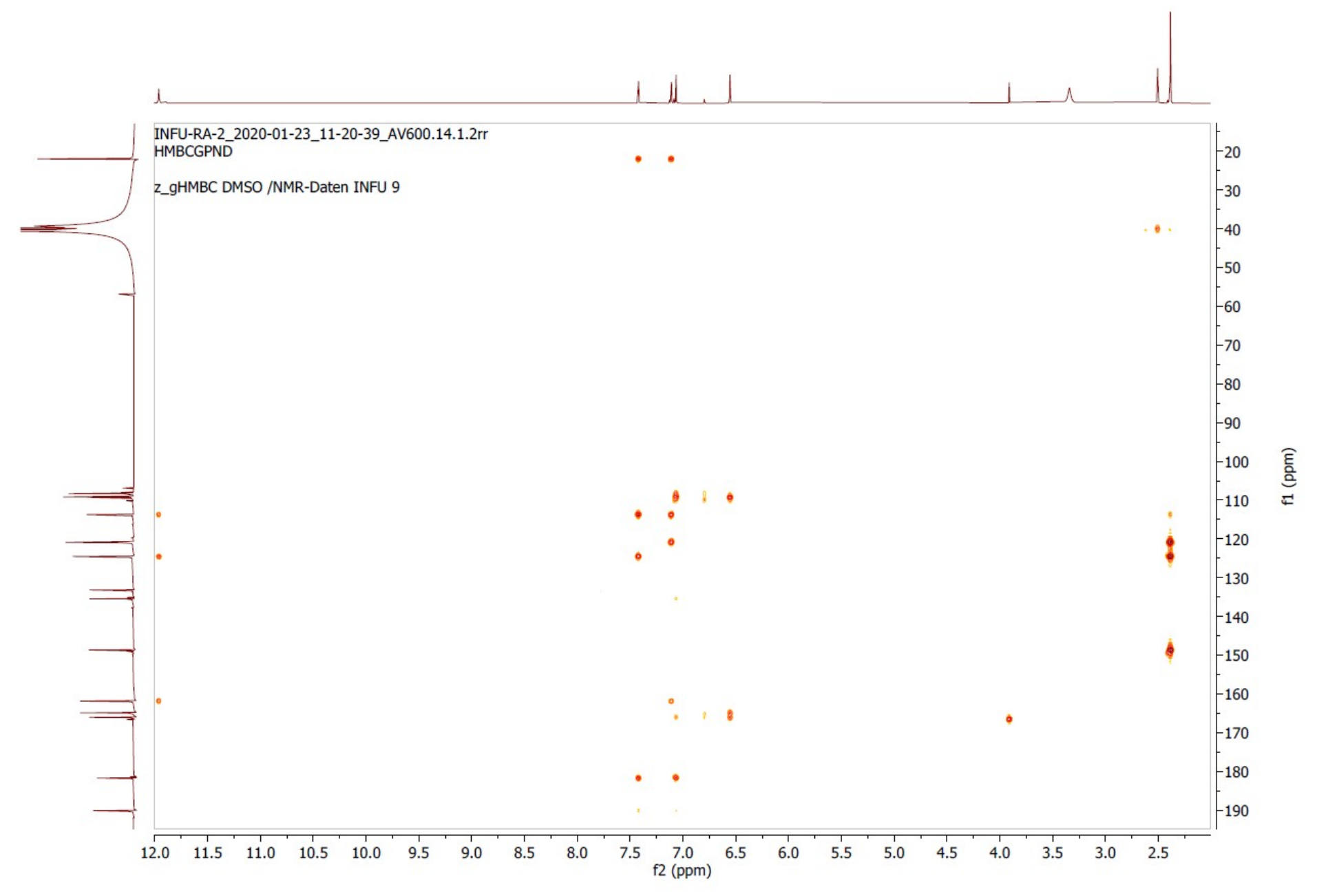

SI10: HMBC spectral data of compound-2. 
Shifa M, Abdissa D, Asere TG. JOTCSA. 2021; 8(1): 21-46.
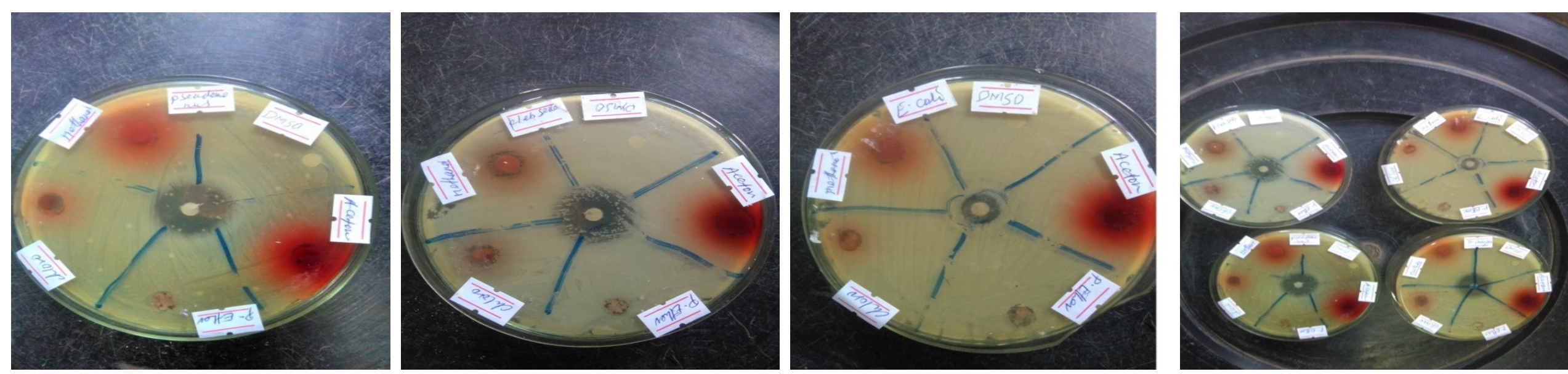

SI11a: Antibacterial activity of crude extract of root of $R$. abyssinicus.
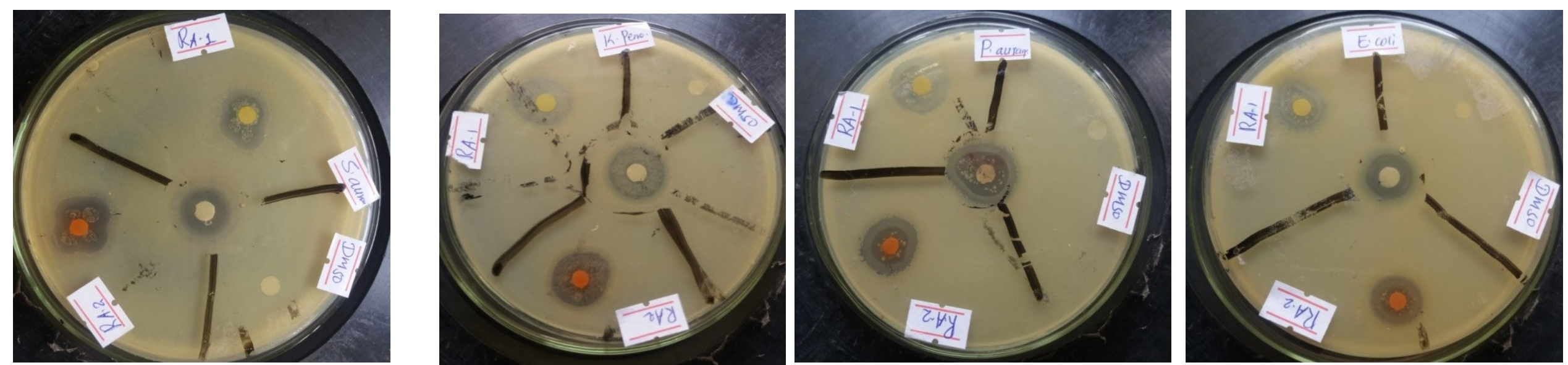

SI11b: Antibacterial activity of isolated compounds (1 and 2) from the root of $R$. abyssinicus. 


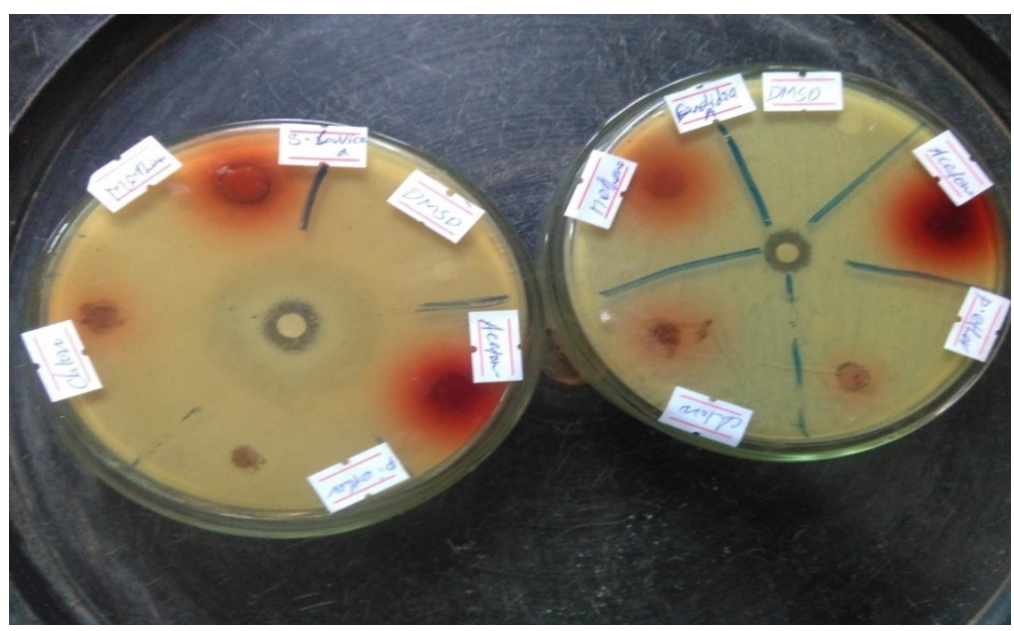

SI12a: Antifungal activity of crude extract of root of $R$. abyssinicus.

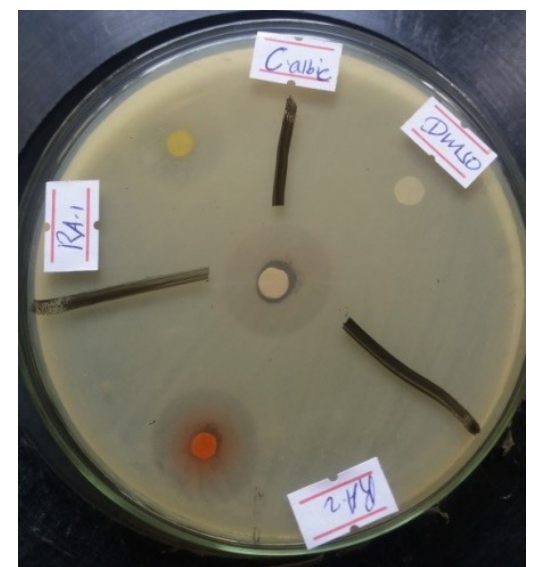

SI12b: Antifungal activity of isolated compounds (1 and 2) from the root of $R$. abyssinicus. 